\title{
Tumor microenvironment-related multigene prognostic prediction model for breast cancer
}

\author{
Kai Hong ${ }^{1}$, Yingjue Zhang ${ }^{2}$, Lingli Yao' ${ }^{1}$, Jiabo Zhang ${ }^{3}$, Xianneng Sheng ${ }^{3}$, Yu Guo ${ }^{3}$ \\ ${ }^{1}$ Medicine School, Ningbo University, Jiangbei, Ningbo 315211, Zhejiang, China \\ ${ }^{2}$ Department of Molecular Pathology, Division of Health Sciences, Graduate School of Medicine, Osaka University, \\ Suita, Osaka 565-0871, Japan \\ ${ }^{3}$ Department of Thyroid and Breast Surgery, Ningbo City First Hospital, Haishu, Ningbo 315010, Zhejiang, China
}

Correspondence to: Yu Guo; email: guovu308@163.com, https://orcid.org/0000-0002-7046-2724

Keywords: breast cancer, biomarkers, differentially expressed genes, risk score, tumor microenvironment

Received: October 28, $2021 \quad$ Accepted: January 14, $2022 \quad$ Published: January 20, 2022

Copyright: (C) 2022 Hong et al. This is an open access article distributed under the terms of the Creative Commons Attribution License (CC BY 3.0), which permits unrestricted use, distribution, and reproduction in any medium, provided the original author and source are credited.

\section{ABSTRACT}

Background: Breast cancer is an invasive disease with complex molecular mechanisms. Prognosis-related biomarkers are still urgently needed to predict outcomes of breast cancer patients.

Methods: Original data were download from The Cancer Genome Atlas (TCGA) and the Gene Expression Omnibus (GEO). The analyses were performed using perl-5.32 and R-x64-4.1.1.

Results: In this study, 1086 differentially expressed genes (DEGs) were identified in the TCGA cohort; 523 shared DEGs were identified in the TCGA and GSE10886 cohorts. Eight subtypes were estimated using non-negative matrix factorization clustering with significant differences seen in overall survival (OS) and progression-free survival (PFS) $(P<0.01)$. Univariate Cox analysis and least absolute shrinkage and selection operator (LASSO) regression analysis were performed to develop a related risk score related to the 17 DEGs; this score separated breast cancer into low- and high-risk groups with significant differences in survival $(P<0.01)$ and showed powerful effectiveness (TCGA all group: 1-year area under the curve $[A U C]=0.729,3$-year AUC $=0.778,5$-year AUC $=0.781$ ). A nomogram prediction model was constructed using non-negative matrix factorization clustering, the risk score, and clinical characteristics. Our model was confirmed to be related with tumor microenvironment. Furthermore, DEGs in high-risk breast cancer were enriched in histidine metabolism (normalized enrichment score $[N E S]=1.49, P<0.05$ ), protein export (NES $=1.58, P<0.05$ ), and steroid hormone biosynthesis signaling pathways (NES $=1.56, \mathrm{P}<0.05$ ).

Conclusions: We established a comprehensive model that can predict prognosis and guide treatment.

\section{INTRODUCTION}

Breast cancer is the most commonly diagnosed malignancy and cause of cancer-related deaths in females [1]. According to the statistics from 2020, approximately 276,480 female breast cancers were diagnosed in the US, and 42,170 patients are expected to die from breast cancer [2]. Despite early diagnosis, abundant treatments, and a decline in the mortality rate of this disease over the past year, patients with advanced and metastatic breast cancer still experience a high mortality rate [3]. Therefore, an effective risk model for breast cancer can play a vital role in individualized therapy.

Breast cancer is strongly correlated with changes in gene status, such as amplifications, downregulation, and mutations. Traditionally, according to immunohistochemistry for estrogen receptor (ER), progesterone receptor (PR), and human epidermal growth factor receptor2 (HER2), breast cancer is classified into the luminal A, luminal B, HER2-positive, and triple-negative subtypes [4]. However, with further exploration of the molecular mechanisms of breast cancer, more detailed 
molecular types have been presented, such as luminal A, luminal B, HER2-enriched, basal-like, normal-like, and claudin-low [5]. Different subtypes have been confirmed to have different prognoses and drug responses. With advances in statistical analysis, multigene signatures are widely used to predict patient prognosis and drug response $[6,7]$. Some multigene prediction models, such as the Oncotype DX 21-gene test, Prediction Analysis of Microarray 50, and 70-gene signature (MammaPrint), have been applied in the clinic [8-10]. The Oncotype DX 21-gene test can evaluate the tumor recurrence and predict chemotherapy responses in patients with ERpositive breast cancer. MammaPrint signature and PAM50 can improve prognostic prediction in breast cancer patients. Nonetheless, despite their high power, these tools only consider gene status, and thus, a model with comprehensive consideration of additional factors is urgently needed.

Breast cancer outcomes are significantly related to factors, such as tumor size, tumor stage, lymph node status, age, tumor tissue receptor status, and gene status. To effectively evaluate prognoses of breast cancer and predict drug responses to guide treatment, we constructed a comprehensive prediction model with varied factors. In this study, we identified differentially expressed genes (DEGs) from The Cancer Genome Atlas (TCGA) and Gene Expression Omnibus (GEO) and performed non-negative matrix factorization (NMF) clustering and a least absolute shrinkage and selection operator (LASSO) regression analysis to construct a nomogram prediction model. We also explored the correlations and potential signaling pathways and discuss a possibly internal mechanism of breast cancer.

\section{MATERIALS AND METHODS}

\section{Data acquisition}

Gene expression, tumor mutation burden, and clinical information datasets of breast cancer were obtained from The Cancer Genome Atlas (TCGA, https://portal.gdc.cancer.gov/) and Gene Expression Omnibus (GEO, https://www.ncbi.nlm.nih.gov/geo/) databases in October 2021. We selected 1208 samples, including 1096 breast cancer samples and 112 normal samples from The Cancer Genome Atlas Breast Invasive Carcinoma (TCGA-BRCA) program. After searching the datasets with more than 150 human breast cancer samples with complete expression profile data, we selected the GSE10886 dataset from the GEO [9].

\section{Analysis of differentially expressed genes}

To identify the DEGs, we used a multi-step approach (Figure 1). The limma and sva $\mathrm{R}$ packages were used for the differential expression analysis (log fold change $[\mathrm{FC}]>1$, false discovery rate $[\mathrm{FDR}]<0.05)$ and batch correction for the TCGA-BRCA [11-15] (Supplementary File 1).

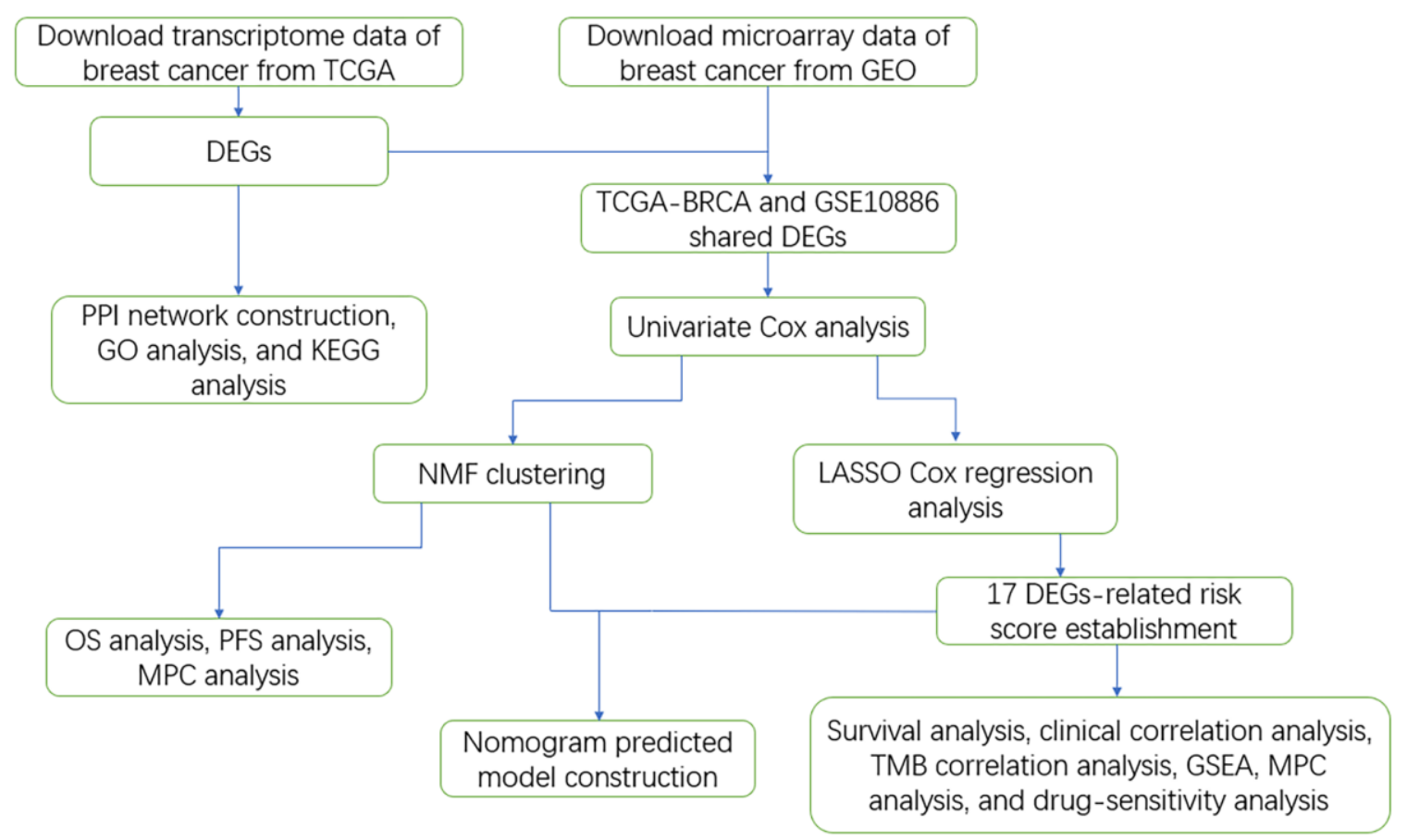

Figure 1. Work flowchart of the study. 


\section{Protein-protein interaction network and enrichment analysis}

The protein-protein interaction (PPI) network for DEGs was constructed using the STRING website tool (https://string-db.org/); the high confidence genes were conserved (interaction score $\geq 0.7$ ), and hub nodes were visualized by R-x64-4.1.1 (Supplementary File 1). Gene ontology (GO) and Kyoto Encyclopedia of Genes and Genomes (KEGG) enrichment analyses were conducted using the clusterprofiler $\mathrm{R}$ package, where $\mathrm{P}<0.05$ [16-18] (Supplementary File 1).

\section{Non-negative matrix factorization clustering}

First, we intersected the TCGA-BRCA and GSE10886 data to obtain the shared DEGs; then, we analyzed the DEGs using the survival and NMF $\mathrm{R}$ packages (Supplementary File 1), through which eight distinct subtypes were identified according to the cophenetic correlation coefficient for the cluster number from 2-10 [19]. Second, the overall survival (OS) and progressionfree survival (PFS) differences among these subtypes, as observed by Kaplan-Meier (K-M) analysis and logrank test, were analyzed using the survival and survminer R packages [20] (Supplementary File 1). Third, the analysis of microenvironment cell populations (MCP) differences among these subtypes was performed using the limma, ggpubr, and MCPcounter R packages [21] (Supplementary File 1).

\section{Nomogram model establishment}

Based on the DEG data, a univariate Cox analysis was performed to identify the survival related genes $(P<0.05)$. A modified LASSO regression analysis was conducted to find the genes most relevant to the OS of breast cancer patients $(P<0.05)$ [22-24] (Supplementary File 1). To verify the accuracy of our risk score predictor, analyses of training, and test groups were performed using data that were randomly obtained from the whole group. The predictive ability of the risk score was evaluated by survival probability curve, receiver operating characteristic (ROC) curve, and the area under the curve (AUC) [25] (Supplementary File 1). The risk computing formula is as follows: Risk score $=\sum_{i=1}^{n} \operatorname{Coef}(i) * \operatorname{Expr}(i)$. In addition, univariate and multivariate analyses were performed to demonstrate the independent predictive ability of the risk score. A nomogram prediction model was established using clinical characteristics, NMF clustering, and risk score to predict the survival of breast cancer patients; the nomogram-predicted probability of the 1-, 3-, and 5-year OS is shown by the calibration curve [26]. To identify the superiority of the nomogram, a decision curve analysis (DCA) was conducted [27] (Supplementary File 1). The R packages survival, survminer, caret, glmnet, timeROC, ggDCA, regplot, and rms were used for these analyses (Supplementary File 1).

\section{Gene set enrichment analysis}

Gene set enrichment analysis (GSEA) was conducted between low- and high-risk score subsets [28] (Supplementary File 1). The "c2.cp.kegg.v7.4. symbols.gmt" was obtained from (https://www.gseamsigdb.org/gsea/index.jsp). Signaling pathways with $P<$ 0.05 and FDR $<0.05$ were considered enriched.

Clinical characteristics, genes, immune cells, and tumor mutation burden correlation analysis

The correlations between risk score and clinical characteristics, known breast cancer genes, immune cells, and tumor mutation burden (TMB) are shown through box plots, correlation matrix, and circular plot generated by ggpubr, corrplot, and circlize R packages, respectively [29] (Supplementary File 1).

\section{Relevance analysis between NMF clustering and risk score}

To further explore the relevance between our novel typing mode and independent predictive factors, a Sankey diagram was plotted using ggalluvial, ggplot2, and dplyr R packages [30-32] (Supplementary File 1).

\section{Immunohistochemistry}

Immunohistochemistry results for risk score related DEGs in breast cancer were obtained from The Human Protein Atlasdatabase (THPA, https://www. proteinatlas.org/).

\section{Chemotherapeutic and immunotherapeutic response prediction}

We predicted the drug response in breast cancer patients based on the Genomics of Drug Sensitivity in Cancer database [33]. Six common chemotherapeutic and immunotherapeutic drugs (paclitaxel, cytarabine, camptothecin, lapatinib, erlotinib, and gefitinib) were selected for the analysis. The $\mathrm{R}$ package pRRophetic was used to conduct the analysis [34] (Supplementary File 1). The inhibitory concentration $\left(\mathrm{IC}_{50}\right)$ was assessed to determine the drug sensitivities. ComBat was used to adjust for batch effects, and the average expression was calculated for repeated genes. 


\section{Statistical analysis}

Statistical analysis was performed using R-x64-4.1.1 and perl-5.32 (Supplementary File 1). Data are presented as means \pm standard deviation. Differences with $P<0.05$ and FDR $<0.05$ were considered statistically significant.

\section{Data availability statement}

All data are available from online database included TCGA (https://portal.gdc.cancer.gov/), GEO (https://www.ncbi.nlm.nih.gov/geo/), THPA (https:// www.proteinatlas.org/), and GSEA (https://www.gseamsigdb.org/gsea/index.jsp).

\section{Ethical statement}

TCGA, GEO, THPA, and GSEA belong to public databases. Patients involved in them all had ethical approval. All analyses of us were based on them, therefore, no ethical issues existed.

\section{RESULTS}

\section{Differentially expressed genes in breast cancer}

The expression of 1086 DEGs was founded in the TCGA-BRCA cohort by comparing breast cancer tissue (1096 tumor samples) with normal tissue (112 normal breast samples) (Figure 2A, 2B).

B
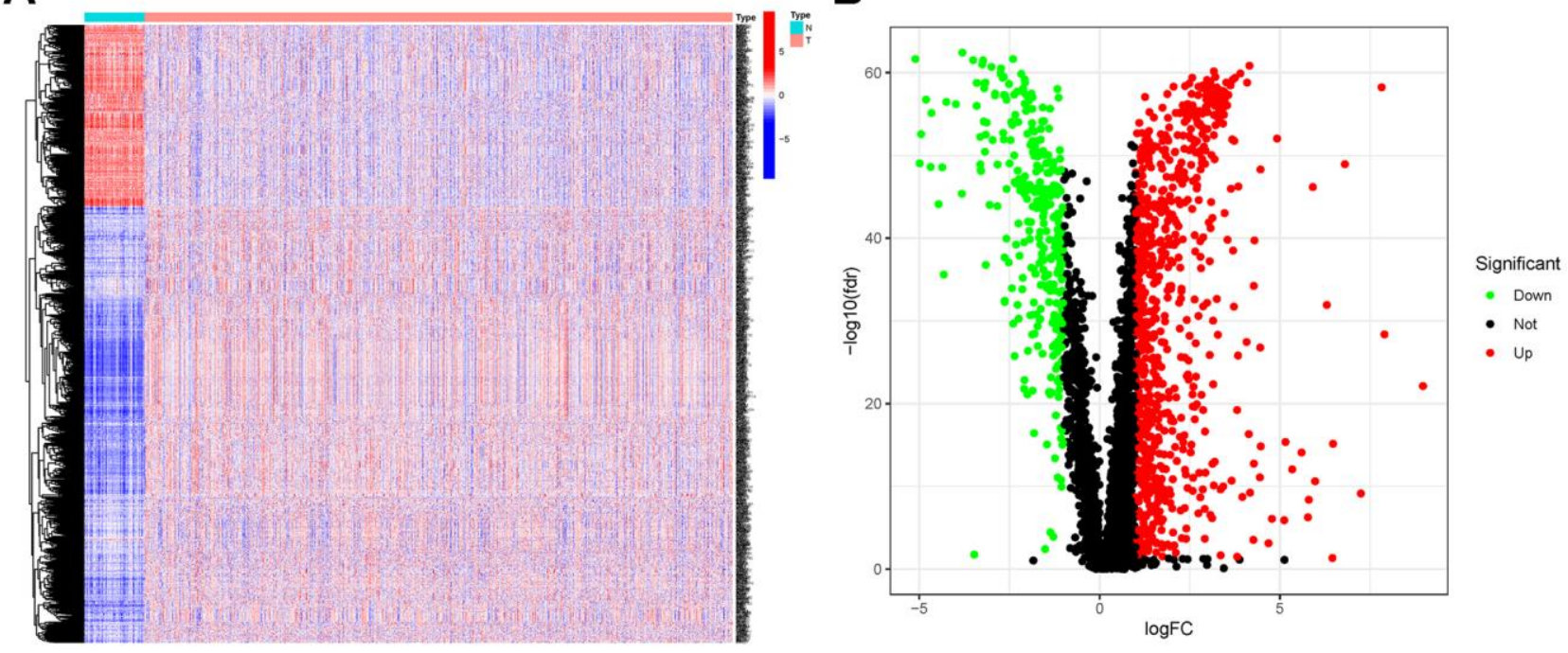

D

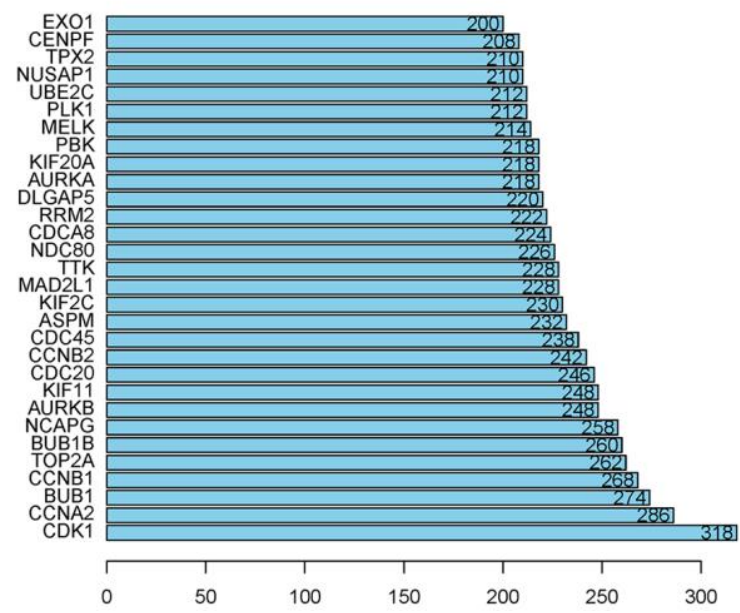

Figure 2. (A, B) DEG analysis for TCGA-BRCA. (C) PPI network of the TCGA-BRCA DEGs. (D) Hub node numbers in the PPI network of the TCGA-BRCA DEGs. Abbreviations: DEGs: differentially expressed genes; TCGA-BRCA: The Cancer Genome Atlas Breast Invasive Carcinoma; PPI network: protein-protein interaction network. 


\section{Protein-protein interaction network analysis and enrichment analysis}

A PPI network was constructed for the TCGA-BRCA DEGs (Figure 2C). The top thirty genes ranked by connectivity degree are shown in Figure 2D. The results showed that CDK1 was the most significant gene with a connectivity degree of 318 , followed by CCNA2 $($ degree $=286)$, BUB1 $($ degree $=274)$, CCNB1 $($ degree $=268$ ), and TOP2A (degree $=262$ ). Biological process analysis showed that "nuclear division," "organelle fission," "chromosome segregation," "mitotic cell cycle phase transition," and "mitotic nuclear division" were significantly relevant to the DEGs (Figure 3A, 3B). Cellular component analysis demonstrated the significantly association between the DEGs with "chromosomal region," "spindle," "collagen-containing extracellular matrix," "condensed chromosome," and "chromosome, centromeric region" (Figure 3A, 3B). According to the molecular function analysis, the DEGs were enriched in "glycosaminoglycan binding," "protein kinase regulator activity," "extracellular matrix structural constituent," "transmembrane receptor protein kinase activity," and "growth factor binding" (Figure 3A, 3B). In the KEGG analysis, the top five enriched pathways were "PI3K-Akt signaling pathway," "cytokine-cytokine receptor interaction," "cell cycle," "human papillomavirus infection," and "MAPK signaling pathway" (Figure 3C, 3D).

\section{Non-negative matrix factorization clustering analysis}

First, a univariate Cox regression analysis was performed using the data of the DEGs to increase the robustness of our cluster $(P<0.01)$. The NMF algorithm was then used to cluster the breast cancer cases based on gene expression, survival time, and survival status. We identified the optimal $\mathrm{k}$ value of 8 with the cophenetic correlation coefficients, and confirmed that the optimal cluster number was 8 (Figure 4A). As shown in
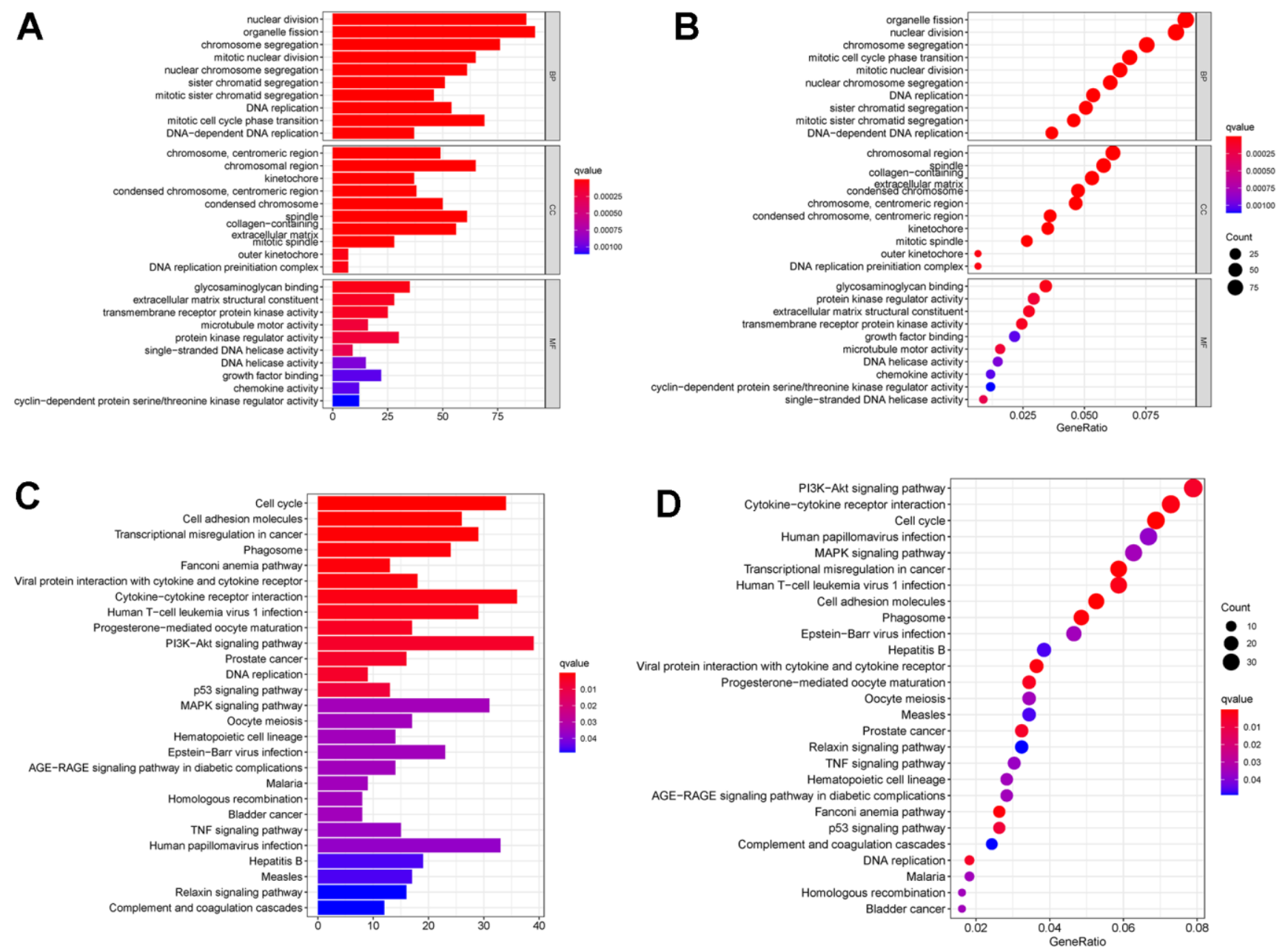

Figure 3. (A, B) GO analysis for TCGA-BRCA DEGs. (C, D) KEGG analysis for TCGA-BRCA DEGs. Abbreviations: GO: Gene Ontology; KEGG: Kyoto Encyclopedia of Genes and Genomes; DEGs: differentially expressed genes; TCGA-BRCA: The Cancer Genome Atlas Breast Invasive Carcinoma. 
A

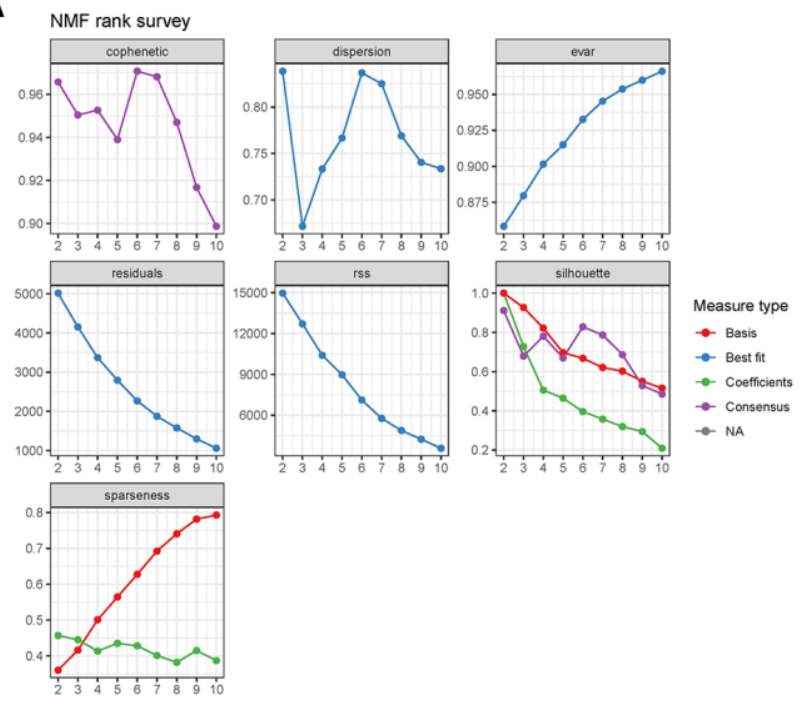

${ }^{8} \quad-$

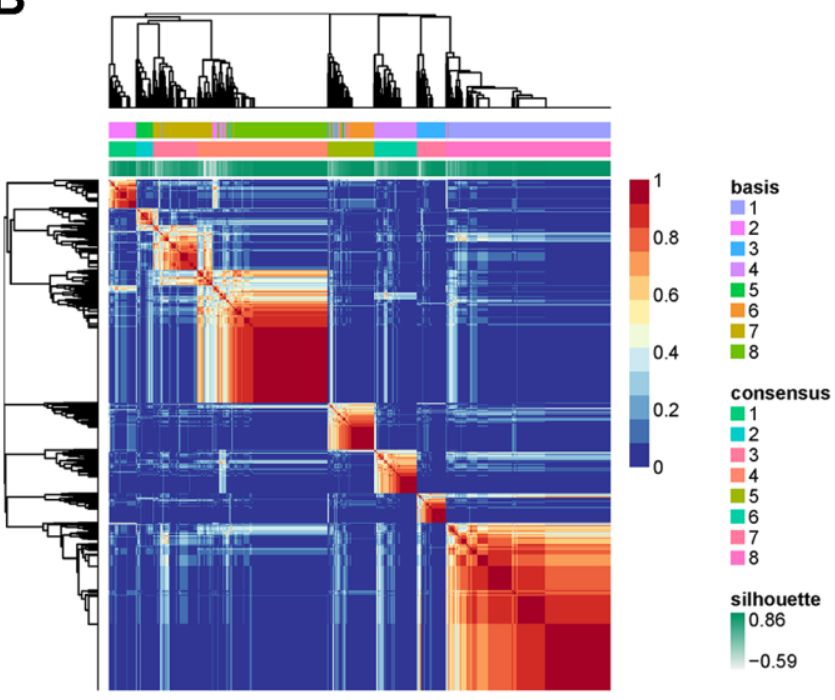

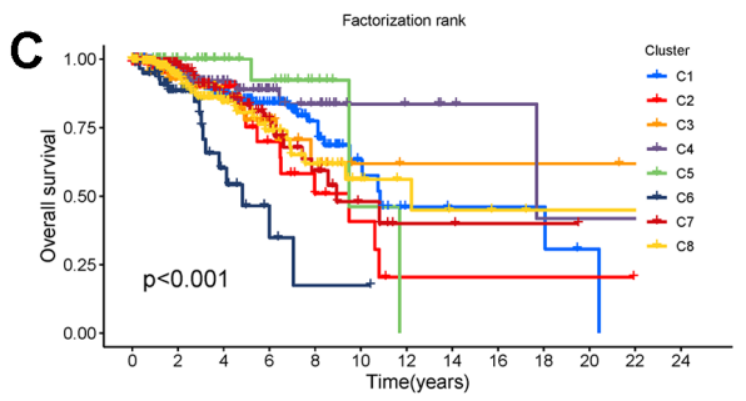

Number at risk

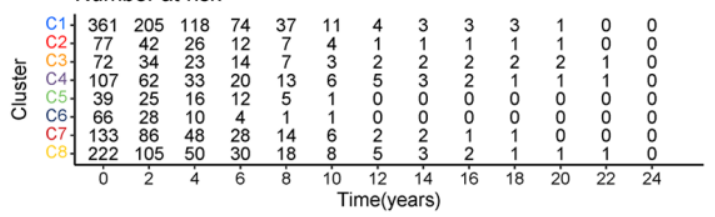

$E$

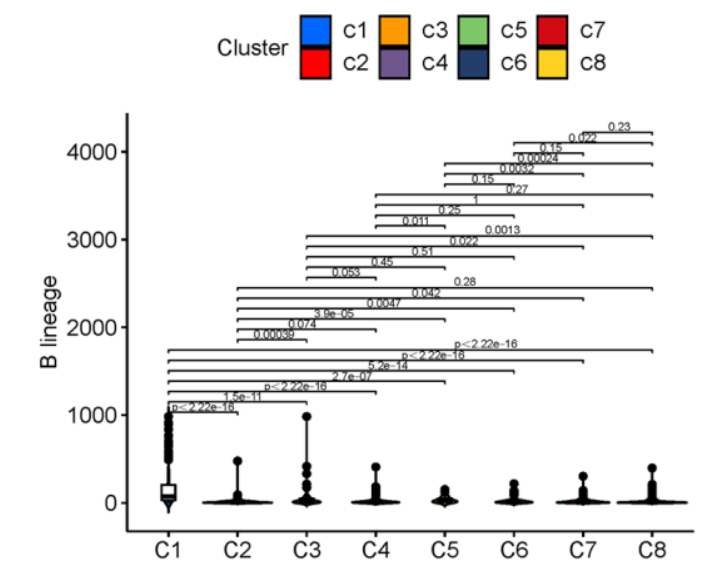

D

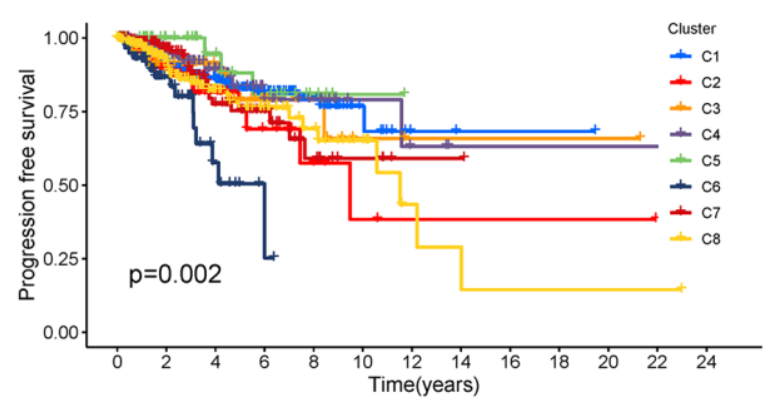

Number at risk

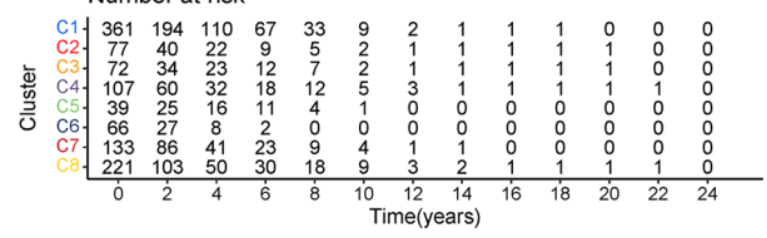

$\mathbf{F} \quad$ Cluster $\square{ }_{c 2}^{c 1} \square{ }_{c 4}^{c 3} \square{ }_{c 6}^{c 5} \square_{c 8}^{c 7}$

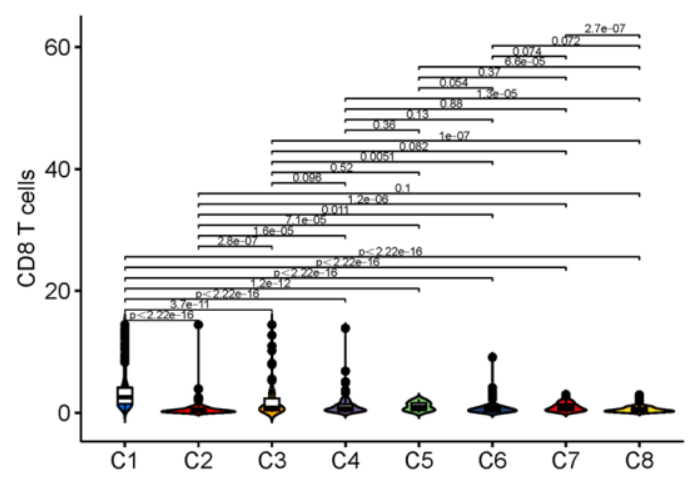

Figure 4. (A) Factorization rank for 2-10 clusters. (B) Heatmap of the gene expression of eight clusters. (C, D) K-M curves for OS and PFS in different subtypes. (E) B lineage cell infiltration in different subtypes. (F) CD8+ T cell infiltration in different subtypes. Abbreviations: K-M: Kaplan-Meier; OS: overall survival; PFS: progression-free survival. 
Figure $4 \mathrm{~B}$, the boundaries of the eight subtypes (C1-C8) are clear, which indicates that the clustering is relatively reliable. According to the OS and PFS curves (Figure 4C, 4D), C4 and C5 breast cancer is associated with the best prognosis, and $\mathrm{C} 6$ breast cancer patients have the worst $(P<0.01)$. MCP counting for eight tissue-infiltrating immune cell types (B lineage, monocytic lineage, cytotoxic lymphocytes, neutrophils, myeloid dendritic cells, NK cells, $\mathrm{T}$ cells, and $\mathrm{CD} 8+\mathrm{T}$ cells) and two stromal cell types (fibroblasts and endothelial cells) was performing using the $\mathrm{R}$ package MCPcounter (Supplementary File 1). We found that $\mathrm{C} 1$ had the greatest abundance of these cells, except neutrophils, in the microenvironment (Figures 4, 5). Moreover, fibroblasts, endothelial cells, and neutrophils were significantly high in $\mathrm{C} 5$, while tissueinfiltrating immune cells were significantly low in C6 (Figure 5B, 5C, 5F).

\section{Construction of the prognostic model}

Based on the 523 DEGs, a univariate Cox analysis was first performed to increase the stability of the results. Subsequently, LASSO regression analysis was performed to identify the 17 DEGs included in the risk assessment model (Figure 6A, 6B). The risk score was calculated according to the following formula: $(0.186995130166584) *$ ExprWNT7B $+(-0.3670682$ $69289688) *$ ExprBCL2A1 + $(0.361699290337736) *$ ExprULBP2 + $(-0.26235003273008) *$ ExprLEF1 + $(0.386283757445905) *$ ExprGABRQ $+(-0.1407101$ $33664929) *$ ExprFXYD3 + $(0.183333746976684) *$ ExprSCG2 + $(-0.388494904628374) *$ ExprFOXJ1 + $(-0.22258520830588) *$ ExprTP63 $+(-0.4505641$ $26981243) *$ ExprRYR1 + $(0.646038331120338) *$ ExprFEZ1 + $(-1.23444095440368) *$ ExprNRG1 + $(0.186015162843612) *$ ExprRGS4 $+(-0.7114998$ $70665385) *$ ExprNFE2 $+(0.174340252592255) *$ ExprHOXC13 + $(-0.249218472277074) *$ ExprMMP25 $+(-0.331805787206587) *$ ExprDTX1. The cut-off value used to divide patients into the low- and high-risk breast cancer was -2.025 . To further verify the accuracy of the risk score predictor, $\mathrm{ROC}$ analysis was performed (Figure 6C-6E). The 1-, 2-, and 3-year AUC values for the whole TCGA cohort were $0.729,0.778$, and 0.781 , respectively, while the 1-, 2-, and 3-year AUC values for the TCGA training cohort were 0.805, 0.782, and 0.793, respectively, and the 1-, 2-, and 3-year AUC values for the TCGA test cohort were $0.627,0.770$, and 0.765 , respectively. According to the K-M plotter, survival differences between the low- and high-risk breast cancer groups in the whole TCGA cohort, TCGA training cohort, and TCGA test cohort were significant $(P<0.01)$ (Figure 6F-6H). In addition, significant differences were also observed in the age $>60$, age $\leq 60$, stage I-II, and stage III-IV subsets (Figure 7).
Moreover, the univariate and multivariate Cox analyses of the relationship between the risk score and clinical characteristics demonstrated that the risk score was an independent predictor of breast cancer (univariate Cox regression: hazard ratio $[\mathrm{HR}]=1.14,95 \%$ confidence interval $[\mathrm{CI}]=1.10-1.17, P<0.01$; multivariate $\mathrm{Cox}$ regression: hazard ratio $=1.13,95 \%$ confidence interval $=1.09-1.17, P<0.01)$ (Table 1). Although the risk score is an independent factor, compared with other clinical characteristics, the AUC value of the risk score was not the highest (Figure 8A). To further improve predictive ability, a nomogram model was constructed using the clinical characteristics, NMF clustering, and risk score. According to the nomogram model, each patient has a total score that can predict the 1-, 3-, and 5-year survival rates (Figure 8B). The calibration curves showed that the nomogram-predicted 1-, 3-, and 5-year OS probabilities were close to the actual OS (Figure 8C). Moreover, the results of DCA showed that our nomogram was the best predictor (Figure 8D).

\section{Potential signaling pathways in the low- and high- risk groups}

To further explore the potential signaling pathways of DEGs in the low- and high-risk groups, GSEA was performed. The GSEA results showed that the histidine metabolism signaling pathway (normalized enrichment score $[\mathrm{NES}]=1.49, P<0.05)$, protein export signaling pathway $(\mathrm{NES}=1.58, \mathrm{P}<0.05)$, and steroid hormone biosynthesis signaling pathway (NES $=1.56, \mathrm{P}<0.05)$ were significantly enriched in the high-risk group (Figure 9A). In contrast, the autoimmune thyroid disease signaling pathway (NES = $-1.88, \mathrm{P}<0.05)$, cell adhesion molecules cams signaling pathway $(\mathrm{NES}=-1.71, \mathrm{P}<0.05)$, chemokine signaling pathway $(\mathrm{NES}=-1.68, \mathrm{P}<$ 0.05), cytokine-cytokine receptor interaction signaling pathway $(\mathrm{NES}=-1.75, \mathrm{P}<0.05)$, and viral myocarditis signaling pathway $(\mathrm{NES}=-1.83, \mathrm{P}<$ 0.05 ) were enriched in the low-risk group (Figure 9B).

\section{Factors correlated with the risk score}

We researched the correlations between the risk score and clinical characteristics and found that age (Figure 9C), $M$ stage (Figure 9D), $N$ stage (Figure 9E), $T$ stage (Figure 9F), and clinical stage (Figure 10A) were significantly associated with the risk score. We then selected 12 known breast cancer-related genes and analyzed their correlations with the risk score. As shown in Figure 10B, significant negative correlations existed between the risk score and TP53, KIT, MCL1, MAP3K1, JAK1, PDCD1, CTLA4, and CD274. Infiltrating $\mathrm{T}$ cells, $\mathrm{CD} 8+\mathrm{T}$ cells, cytotoxic 
A $\quad$ cluster $\square \begin{aligned} & c 1 \\ & c 2\end{aligned} \square$ c4 $\square \square$ c6 $\square$ c5 $\square$ c8

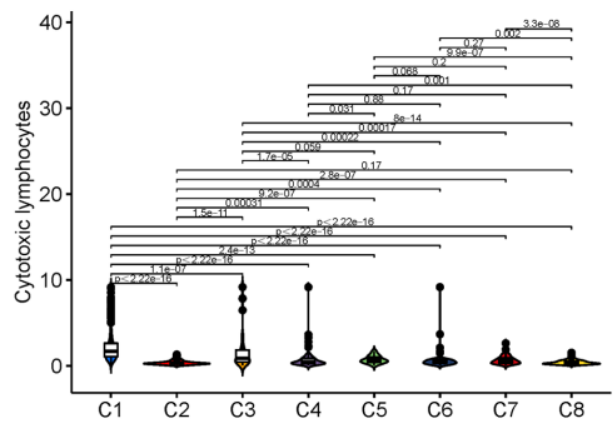

C $\quad$ Cluster $\square \begin{aligned} & c 1 \\ & c 2\end{aligned} \square \begin{aligned} & c 3 \\ & c 4\end{aligned} \square \begin{aligned} & c 5 \\ & c 6\end{aligned} \square$ c8
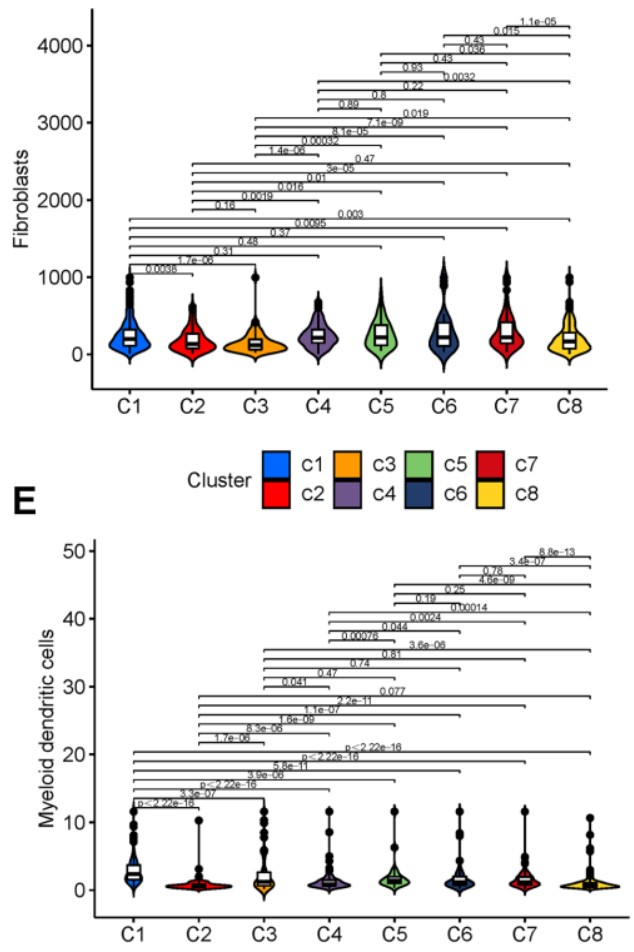

G

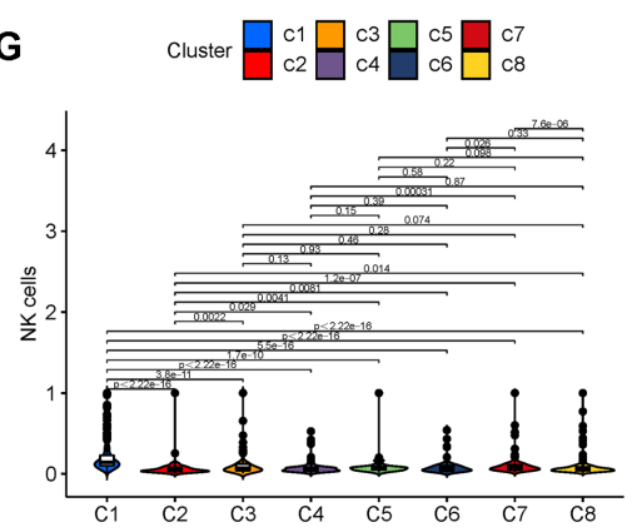

B $\quad$ cluster $\square$ c1 $\square$ c2 $\square$ c4 $\square \square$ c6 $\square \square$ c8

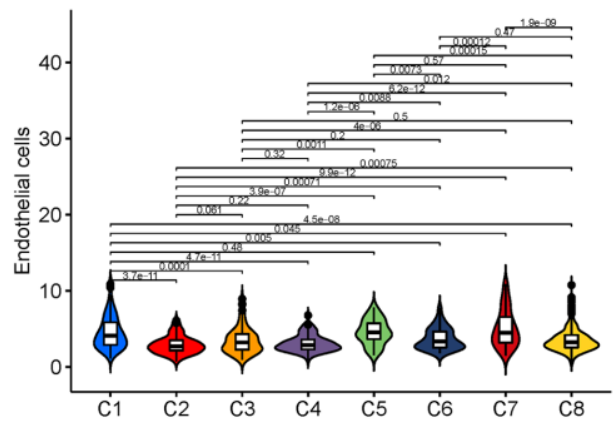

D $\quad$ cluster $\square$ c2 $\square \square$ c4 $\square$ c5 $\square$ c5 $\square$ c8
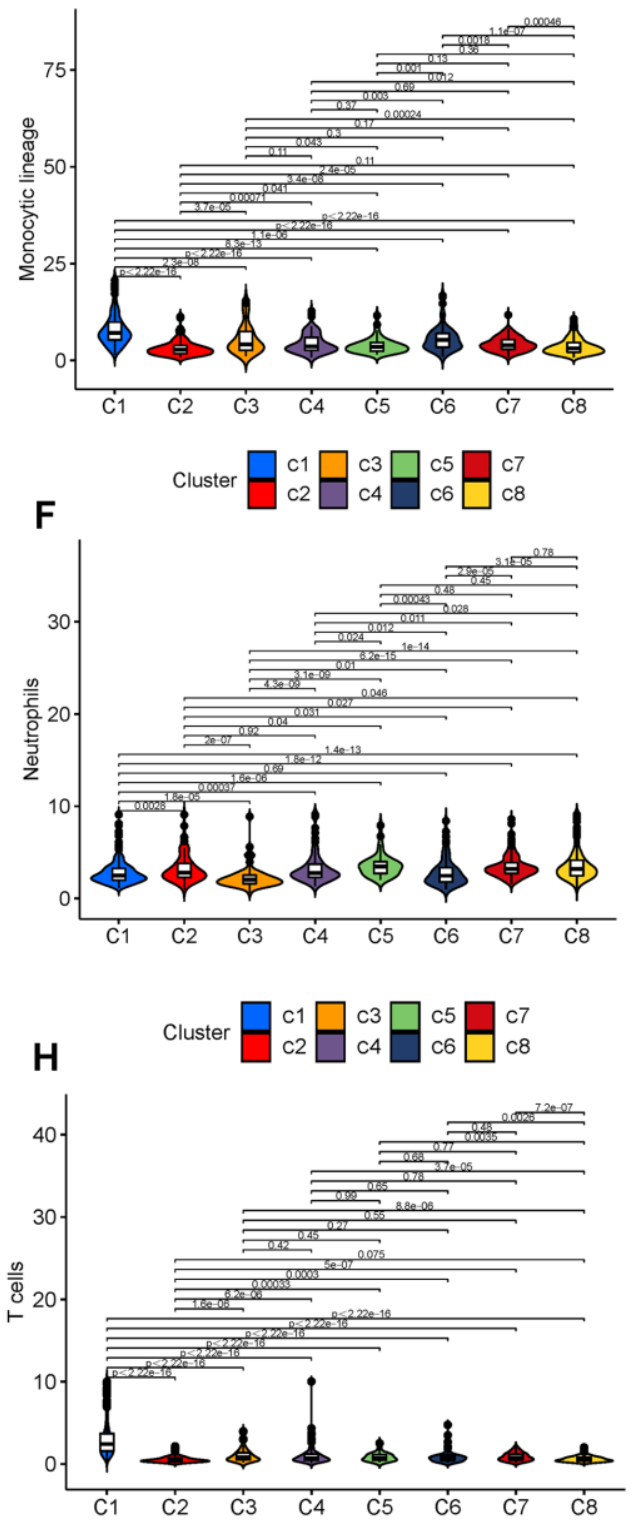

Figure 5. (A) Cytotoxic lymphocyte infiltration in different subtypes. (B) Endothelial cell infiltration in different subtypes. (C) Fibroblast infiltration in different subtypes. (D) Monocytic lineage cell infiltration in different subtypes. (E) Myeloid dendritic cell infiltration in different subtypes. (F) Neutrophil infiltration in different subtypes. (G) NK cell infiltration in different subtypes. (H) T cell infiltration in different subtypes. 


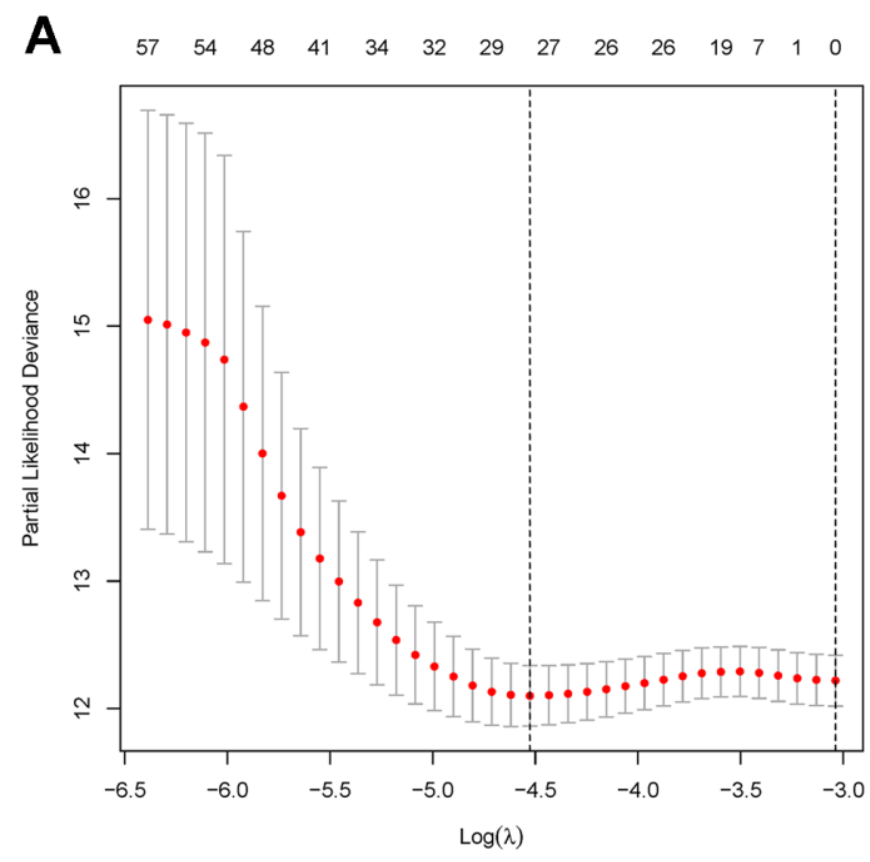

C

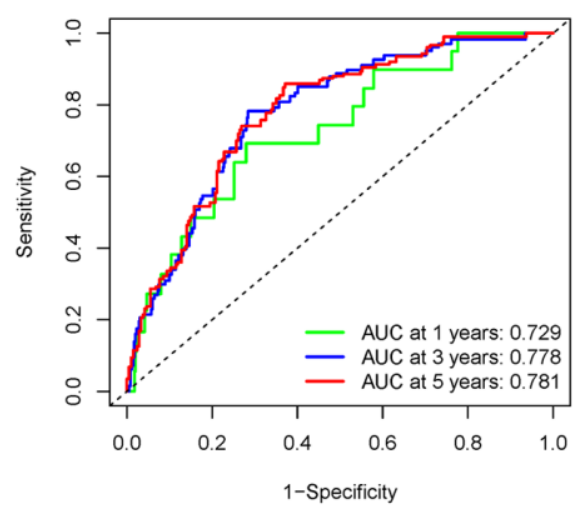

$\mathbf{F}$

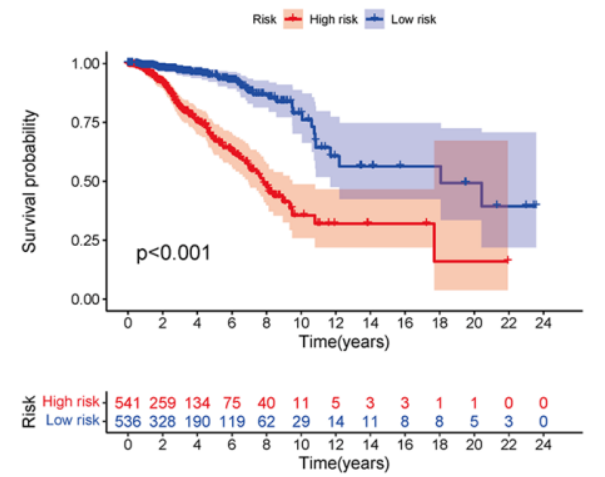

G

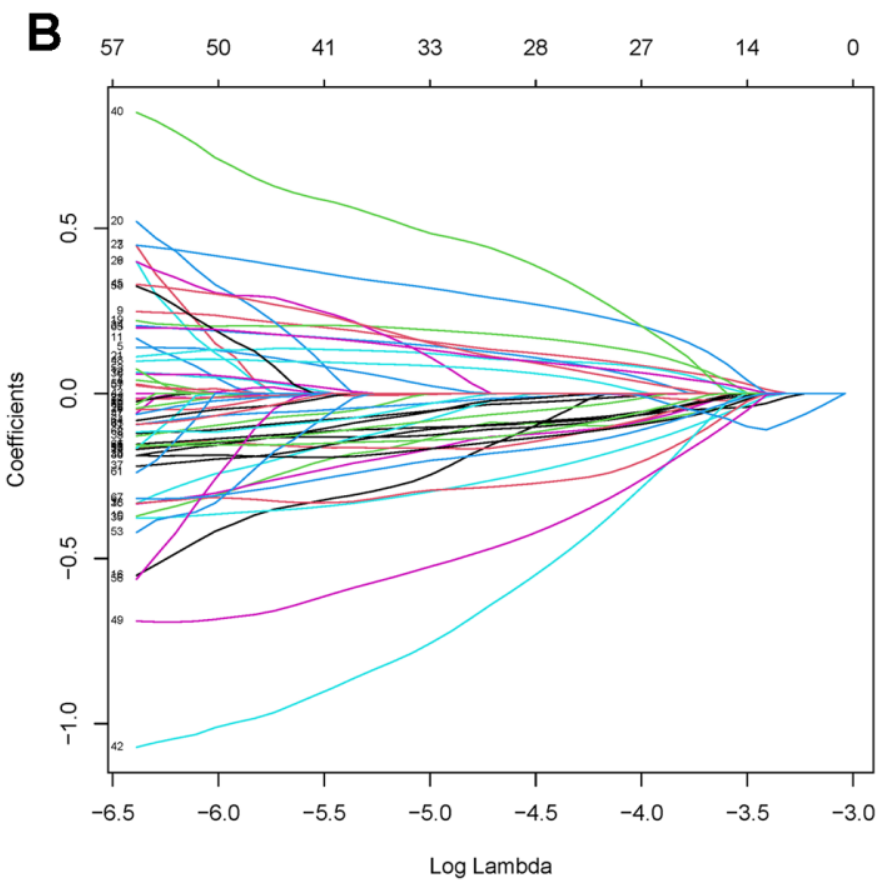

E
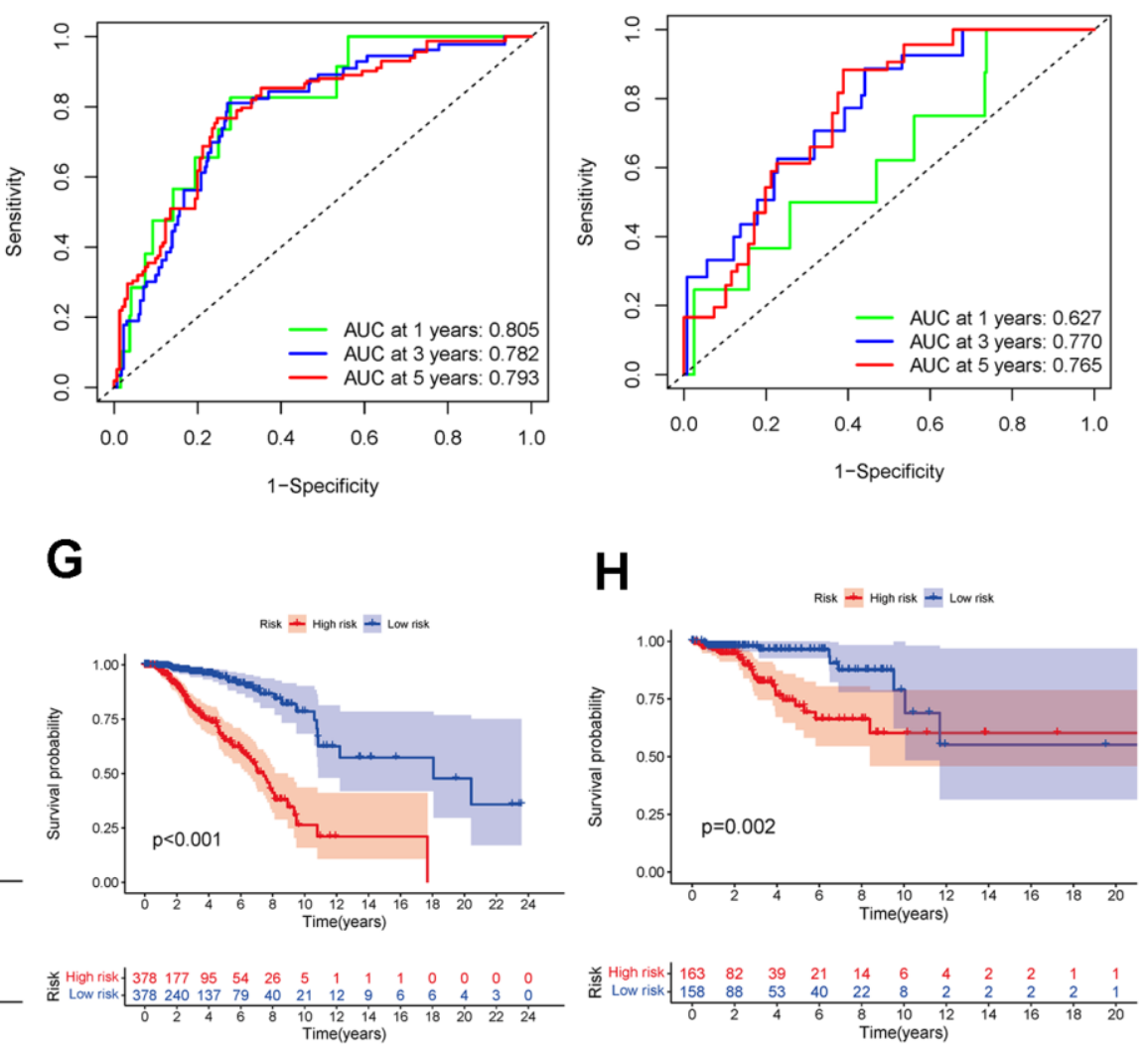

Figure 6. (A, B) The LASSO regression analysis identified 17 DEGs mostly related to prognosis. (C-E) The 1-, 3-, and 5-year ROC analyses in the whole TCGA-BRCA cohort, TCGA-BRCA training cohort, and TCGA-BRCA test cohort. (F-H) K-M curves of OS for lowand high-risk breast cancers in the whole TCGA-BRCA cohort, the TCGA-BRCA training cohort, and TCGA-BRCA test cohort. Abbreviations: LASSO: least absolute shrinkage and selection operator; DEGs: differentially expressed genes; K-M: Kaplan-Meier; TCGA-BRCA: The Cancer Genome Atlas Breast Invasive Carcinoma; ROC: receiver operating characteristic. 
lymphocytes, B lineage cells, NK cells, monocytic lineage cells, and myeloid dendritic cells were significantly negatively correlated with the risk score, while the fibroblasts were significantly positive correlated to the risk score (Figure 10C). In addition, we did not find a significant correlation between the risk score and TMB (Figure 10D).

\section{Correlation between NMF clustering and the risk score}

To connect the NMF clustering and risk score, we generated a Sankey diagram (Figure 10E). The plot showed that more dead patients had high-risk scores,

A Patients with $>60$

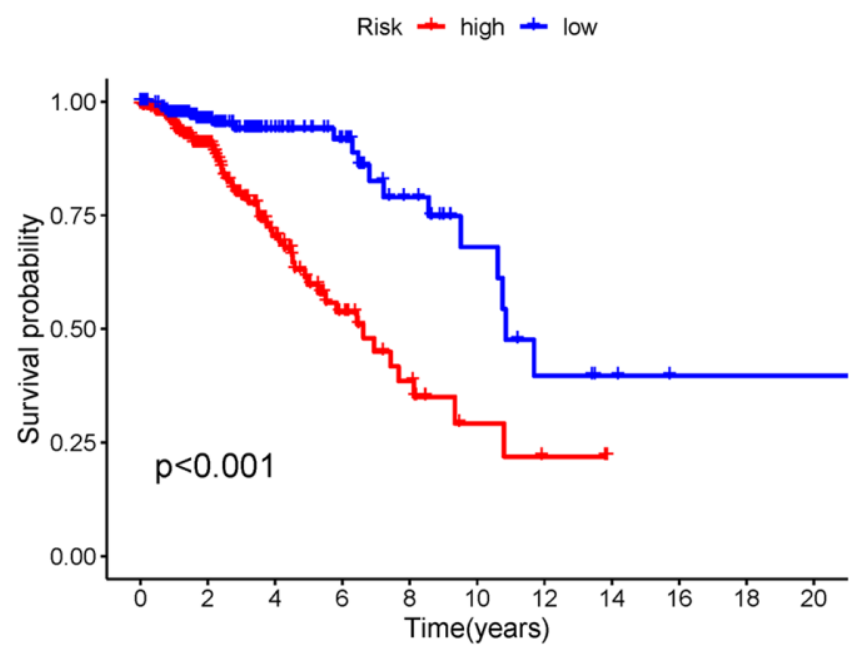

C Patients with Stage I-II

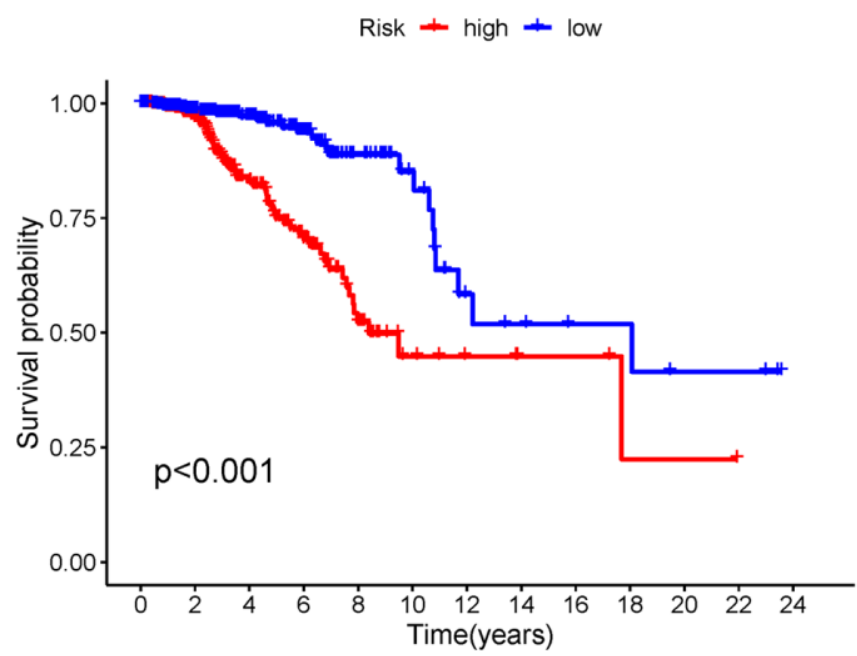

which further demonstrated the reliability of the risk score. Furthermore, the C2 and C6 subtypes mainly contained high-risk scores breast cancer and had the worse prognoses according to the survival curves, while the $\mathrm{C} 4$ and $\mathrm{C} 5$ subtypes included more low-risk breast cancer had better prognoses. These results demonstrated the accuracy of both the novel typing mode and the predictive factor.

\section{Validation of the risk score-relevant genes in breast cancer tissue}

Immunohistochemistry demonstrated the expression of DTX1, FEZ1, FOXJ1, FXYD3, HOXC13, LEF1,

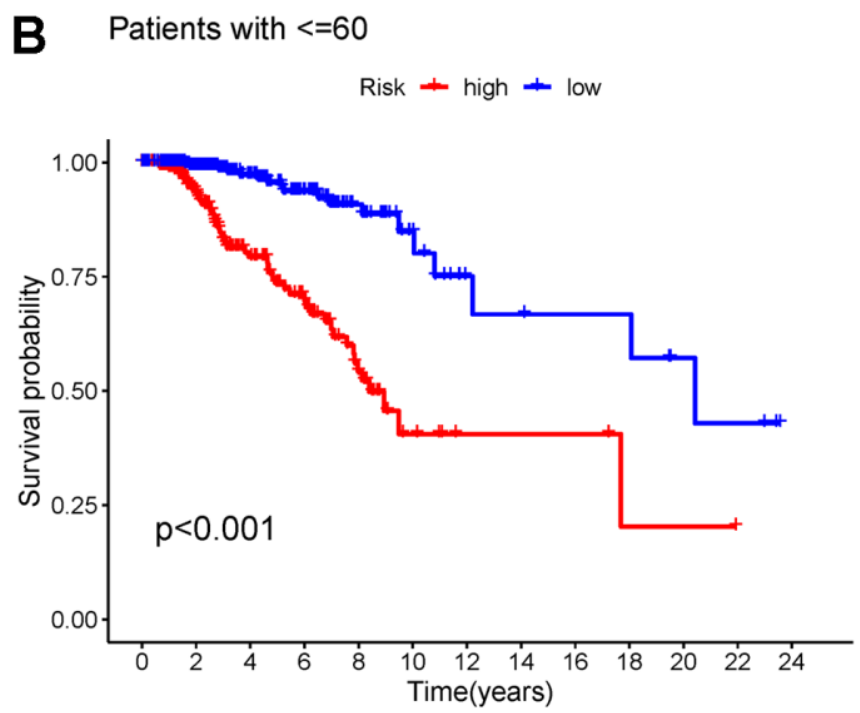

D Patients with Stage III-IV

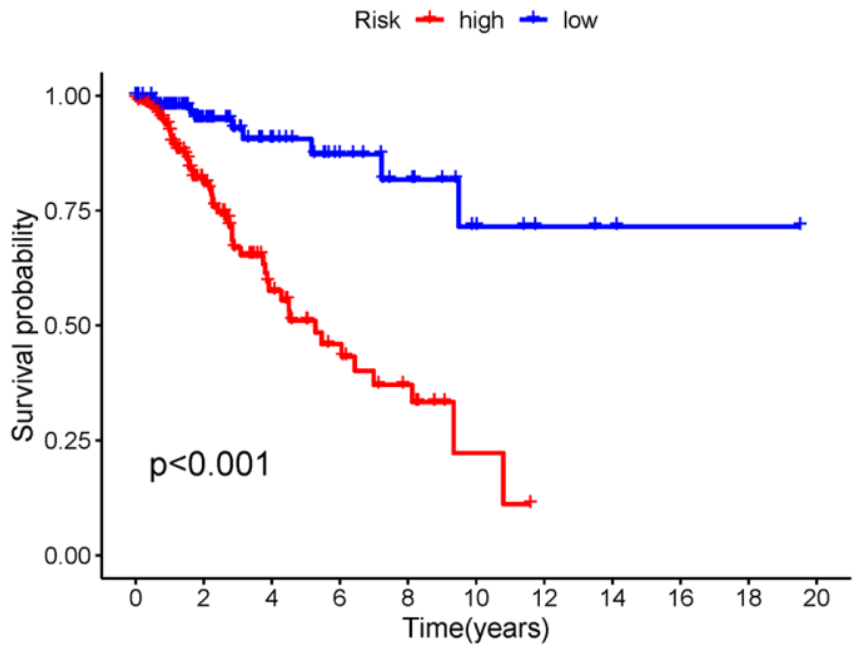

Figure 7. (A, B) K-M curves of OS for breast cancer patients age $>60$ and age $\leq 60$ in the low- and high-risk groups. (C, D) K-M curves of OS for stage I-II and stage III-IV breast cancer in the low- and high-risk groups. Abbreviations: K-M: Kaplan-Meier; OS: overall survival. 
Table 1. Univariate and multivariate Cox analyses.

\begin{tabular}{lcccc}
\hline \multicolumn{5}{c}{ Univariate Cox analysis } \\
\hline id & HR & HR.95L & HR.95H & p-value \\
\hline Age & 1.034397 & 1.01977 & 1.049234 & $3.25 \mathrm{E}-06$ \\
Stage & 2.109207 & 1.668588 & 2.666178 & $4.32 \mathrm{E}-10$ \\
$\mathrm{~T}$ & 1.570708 & 1.265938 & 1.94885 & $4.09 \mathrm{E}-05$ \\
$\mathrm{M}$ & 6.027352 & 3.314181 & 10.96167 & $3.94 \mathrm{E}-09$ \\
$\mathrm{~N}$ & 1.67166 & 1.393874 & 2.004807 & $3.00 \mathrm{E}-08$ \\
Risk score & 1.136899 & 1.103803 & 1.170987 & $1.71 \mathrm{E}-17$ \\
\hline \multicolumn{5}{c}{ Multivariate Cox analysis } \\
\hline id & HR.95L & HR.95H & p-value \\
\hline Age & 1.031857 & 1.016637 & 1.047306 & $3.53 \mathrm{E}-05$ \\
Stage & 1.450661 & 0.855984 & 2.458478 & 0.166909 \\
$\mathrm{~T}$ & 1.068995 & 0.787655 & 1.450826 & 0.668532 \\
$\mathrm{M}$ & 1.383885 & 0.596304 & 3.211683 & 0.449431 \\
$\mathrm{~N}$ & 1.305108 & 0.977835 & 1.741916 & 0.070638 \\
Risk score & 1.12811 & 1.091573 & 1.16587 & $7.18 \mathrm{E}-13$ \\
\hline
\end{tabular}

HR, hazard ratio; HR.95L, hazard ratio 95\% Cl low; HR.95H, hazard ratio 95\% $\mathrm{Cl}$ high.

MMP25, NFE2, NRG1, SCG2, TP63, and ULBP2 (Figure 11).

\section{Differences in drug response between the low- and high-risk breast cancer groups}

As shown in Figure 12, the high-risk breast cancer cohort showed a significantly higher response to paclitaxel, cytarabine, camptothecin, erlotinib, and gefitinib, while the low-risk cohort showed a significantly better response to lapatinib.

\section{DISCUSSION}

Breast cancer is a heterogeneous disease with a high incidence rate and poor prognosis [35]. As the molecular mechanism of breast cancer is complex, continuous studies aim to identify better molecular typing of breast cancer. Wang et al. [7] developed a five-gene (EDN2, CLEC3B, SV2C, WT1, and MUC2) prognostic signature using LASSO Cox regression analysis. Gao et al. [6] developed a pyroptosis-related lncRNA-associated (AC121761.2, AC027307.2, LINC01871, U73166.1, AL513477.2, AC005034.5 and AL451085.2) predictive model using LASSO Cox regression analysis. However, these risk models only considered the molecular status. Indeed, breast cancer is a complicated disease that requires additional considerations. Our nomogram is a comprehensive prognostic prediction tool that includes clinical characteristics, NMF clustering-based typing, and the risk score. Many multigene analysis-based models have been published in the last decade [36-38]. NMF clustering is a novel typing method that is rarely used in breast cancer and with which we can achieve a more detailed typing to predict more accurate prognoses for breast cancer patients.

Based on the shared DEG expression and survival data of breast cancer patients, eight novel subtypes were identified. According to the K-M survival plots, C4 and $\mathrm{C} 5$ breast cancer had a better OS and PFS, whereas C6 had an obviously poor prognosis. Notably, C4 and C5 breast cancer had high neutrophil infiltration, while C6 breast cancer had lower levels of neutrophil infiltration. As one of the most important immune cell types, neutrophils play a vital role in cancer progression, such as by directly eliminating cancer cells, releasing factors that affect the tumor microenvironment (TME), and producing reactive oxygen and nitrogen species [39]. These anti-tumor effects might account for the better prognosis of $\mathrm{C} 4$ and $\mathrm{C} 5$ breast cancer. Moreover, we found that $\mathrm{C} 4$ and C5 breast cancer had a low number of monocytes and that C6 breast cancer had highest monocyte infiltration. Mononuclear cells are precursors of tumor-associated macrophages (TAMs) which comprise the most abundant proportion of tumorinfiltrating immune cells [40]. Substantial evidence showed that TAMs are highly associated with poor prognosis in cancer $[41,42]$. The potential mechanism of TAMs is complicated and includes tumor promotion, an increase in cancer resistance, and promotion of cancer cell migration [43-46]. Undoubtedly, mononuclear cells are important in the breast cancer microenvironment, as they have the 
A

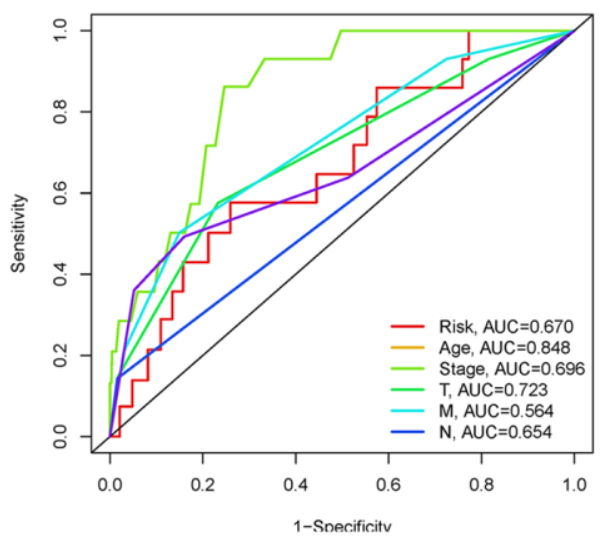

B
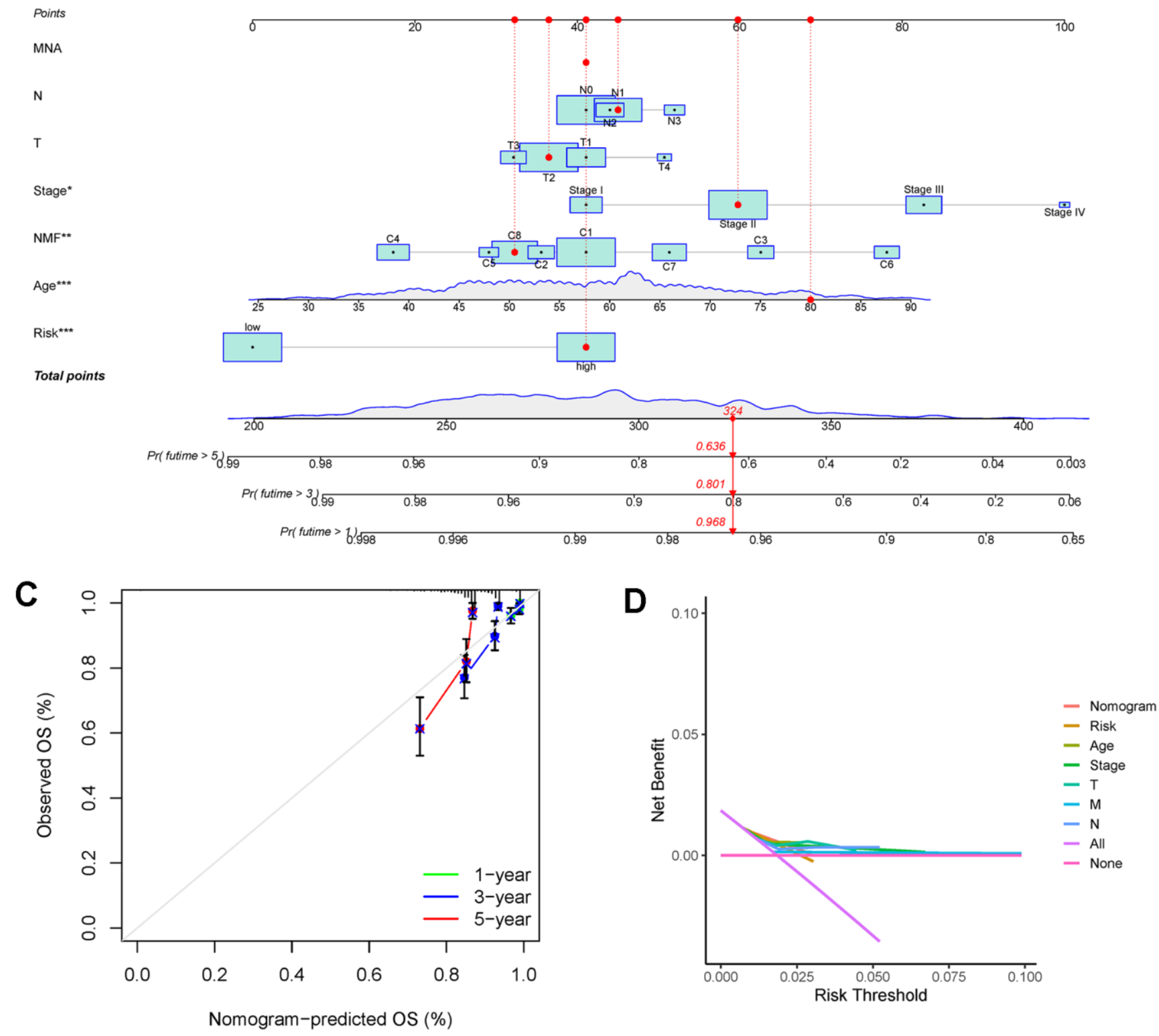

Figure 8. (A) Calculation of the AUC for risk score, age, stage, T, M, and N. (B) Nomogram-predicted model for breast cancer. (C) Calibration plots for 1-, 3-, and 5-year survival probabilities. (D) DCA of the nomogram, risk score, age, stage, $\mathrm{T}$ stage, $\mathrm{M}$ stage, and $\mathrm{N}$ stage. Abbreviations: AUC: area under the curve; DCA: decision curve analysis. 
A
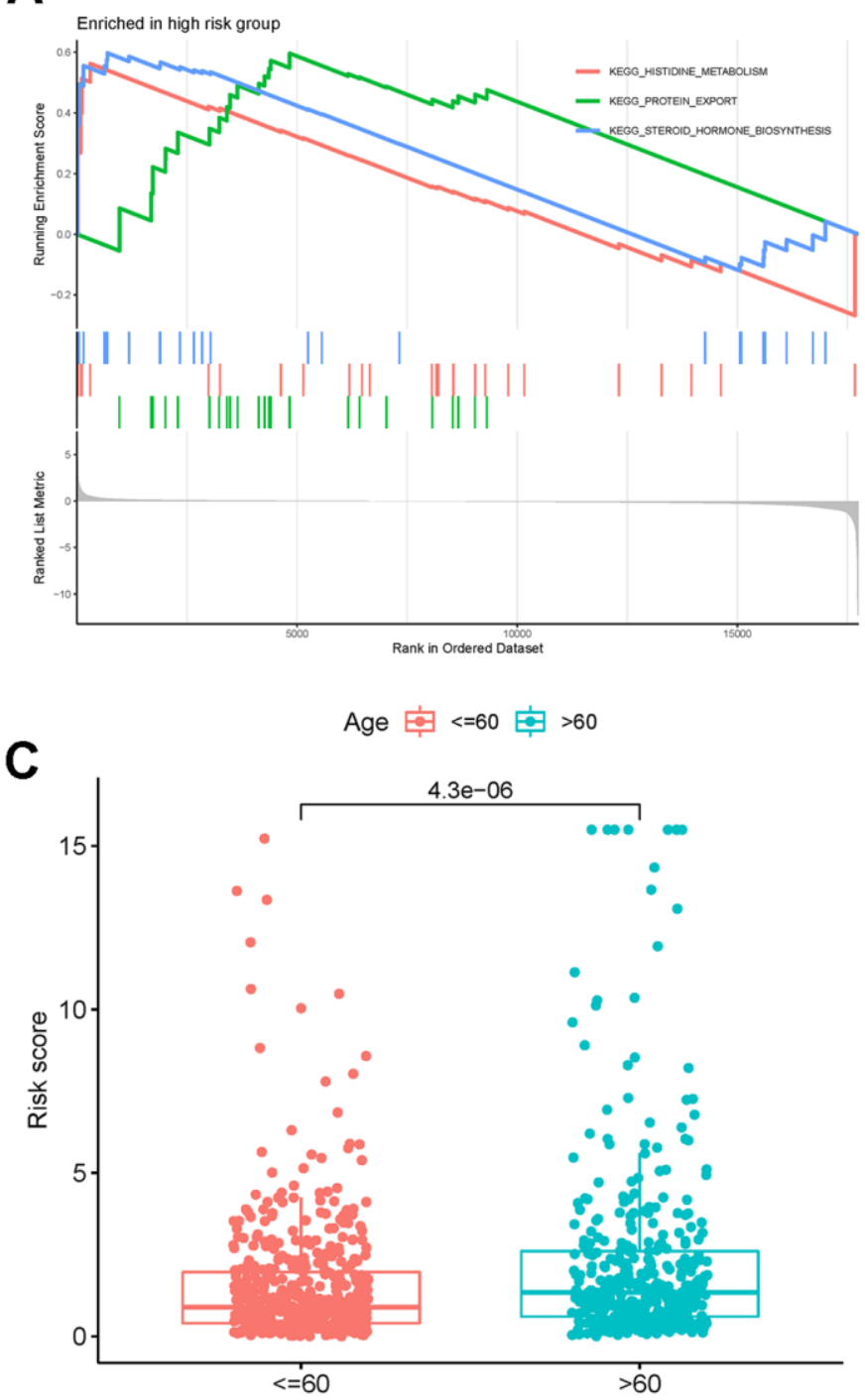

N 守 No

E

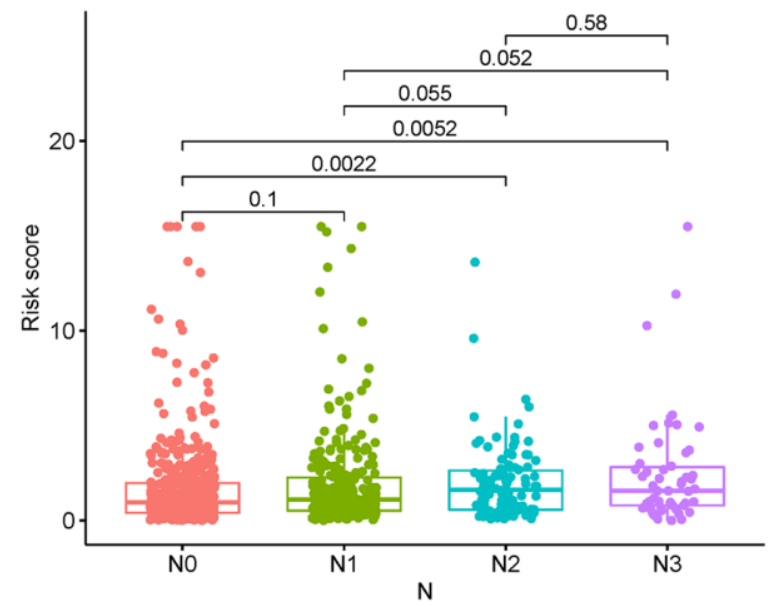

B

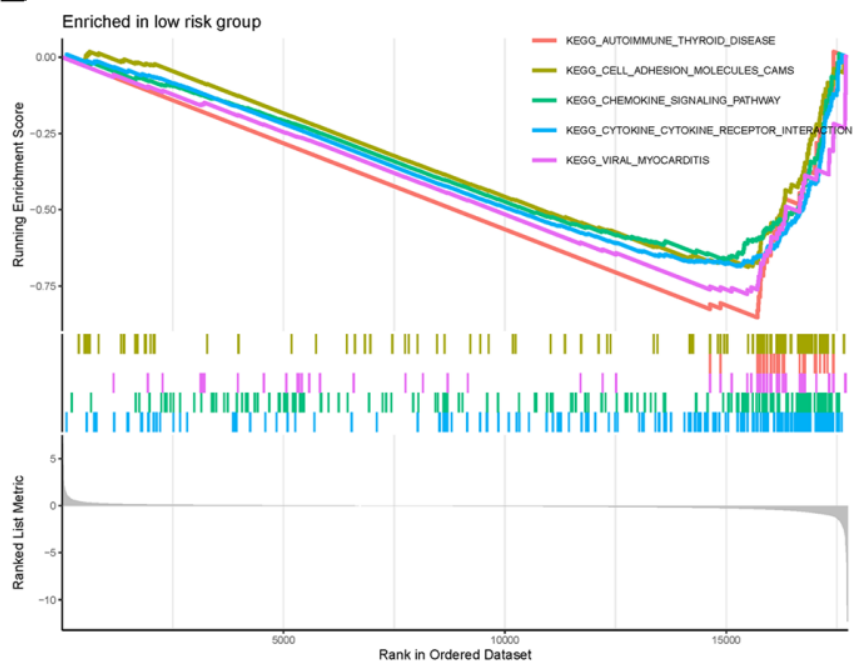

$\mathrm{M}$ 安 M0 审 M1

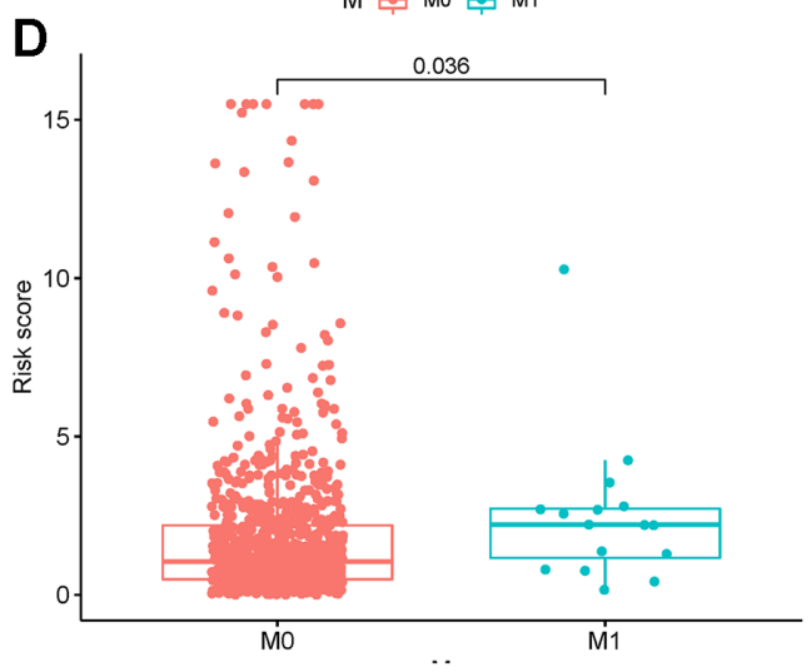

T 후 T1 安 $\mathrm{T} 2$ 审 T3 후 T4

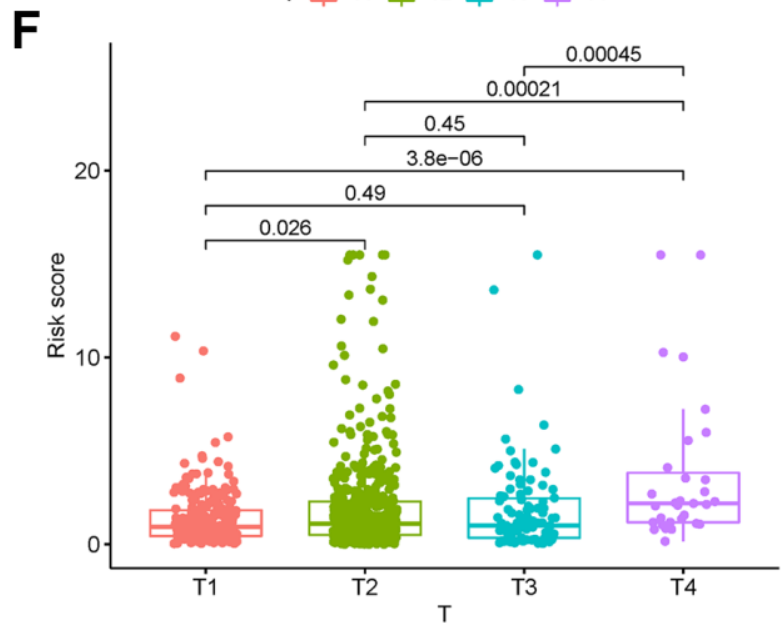

Figure 9. (A, B) GSEA in low- and high-risk breast cancer. (C-F) Correlation analyses of the risk score with age, $\mathrm{M}$ stage, $\mathrm{N}$ stage, and T stage. Abbreviations: GSEA: gene set enrichment analysis. 
A

Stage 宊 Stage I 审 Stage II 审 Stage III 宊 Stage IV
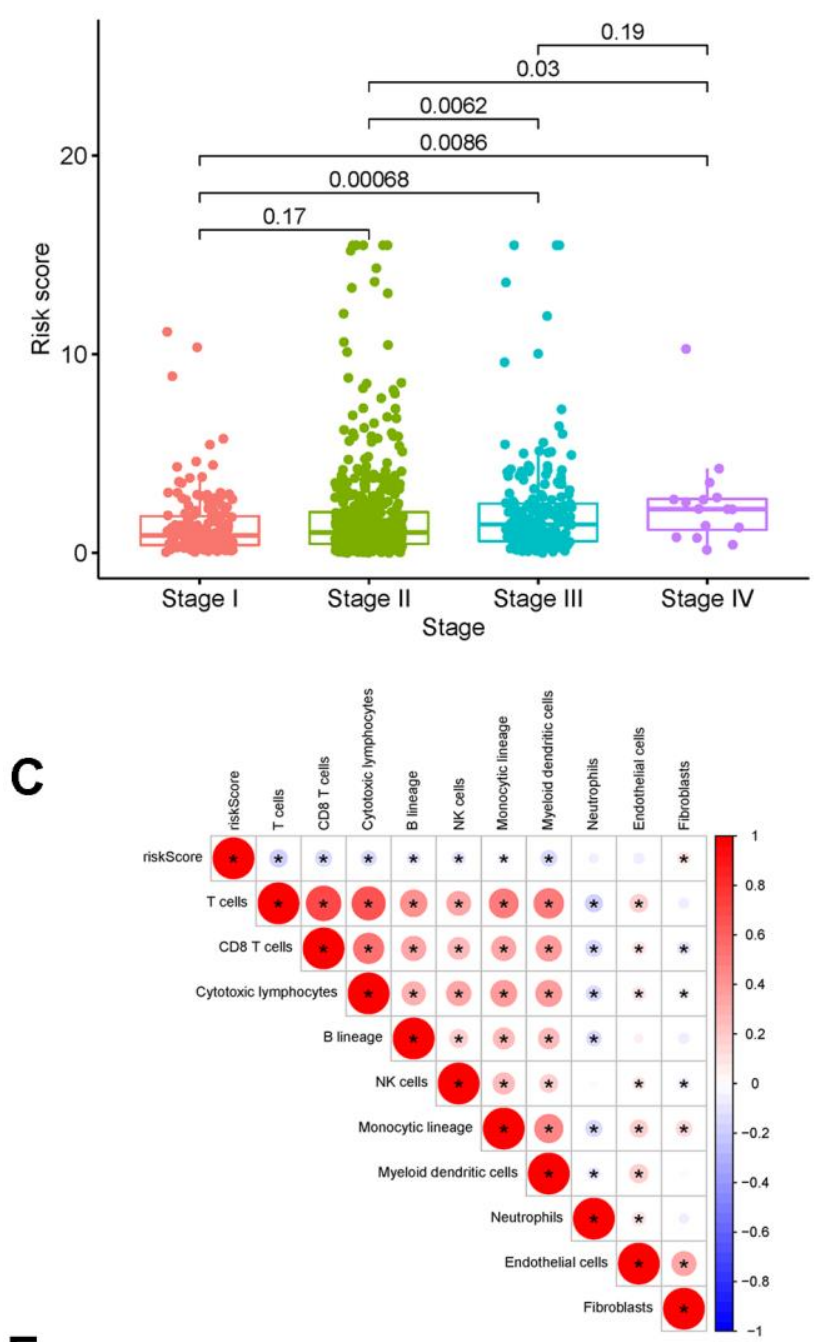

E

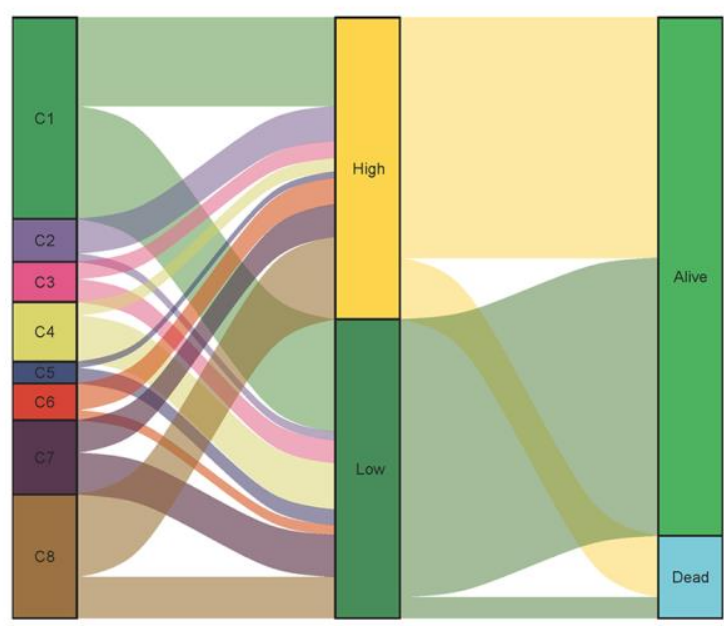

NMF

Risk
B

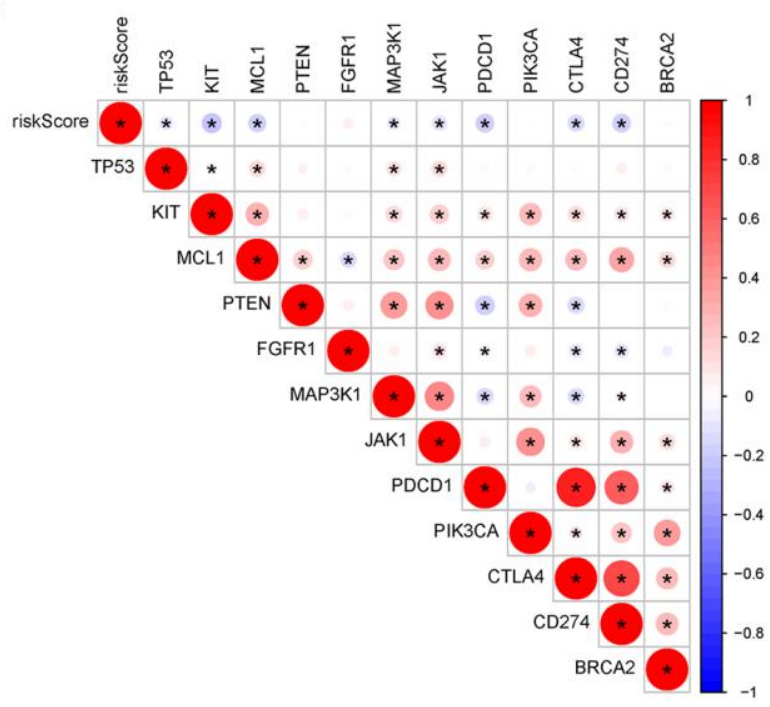

D

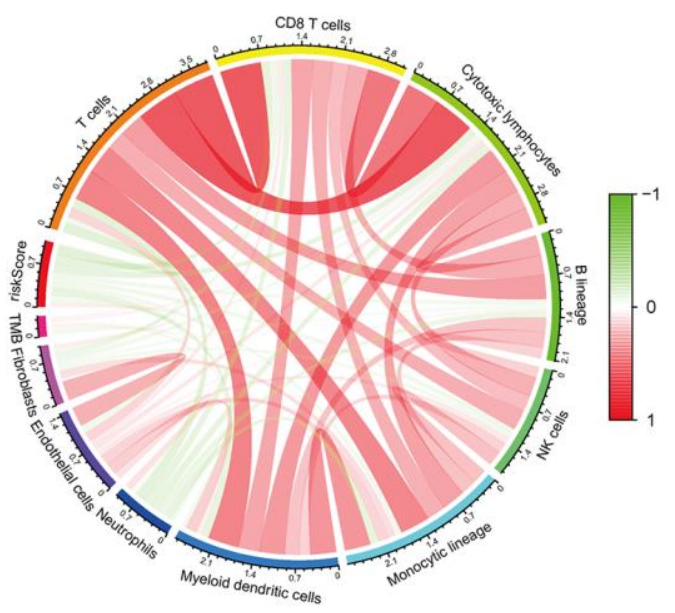

Figure 10. Correlation analysis of (A) Risk score and tumor stage. (B) Risk score and breast cancer-associated genes. (C) Risk score and immune cell infiltration. (D) TMB. (E) NMF clustering and risk score. Abbreviations: TMB: tumor mutation burden; NMF: non-negative matrix factorization. 
A

D

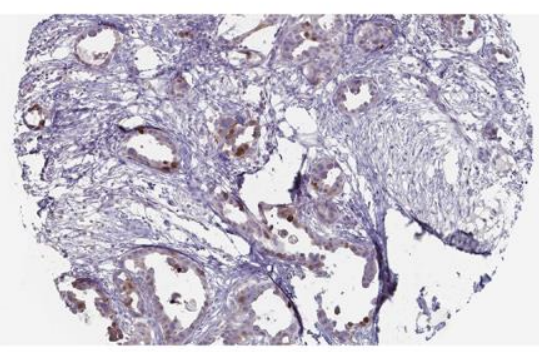

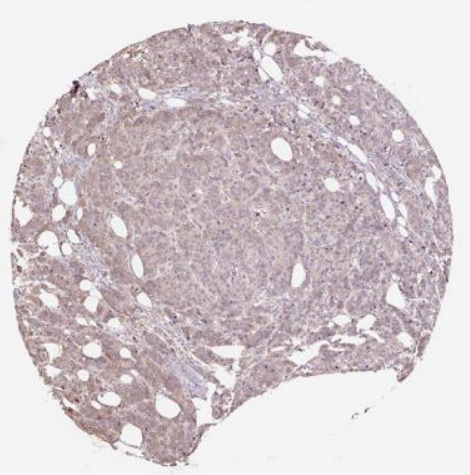

B

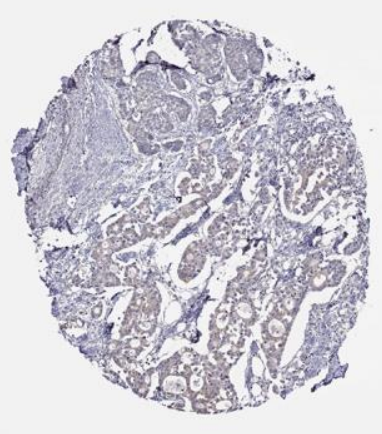

E

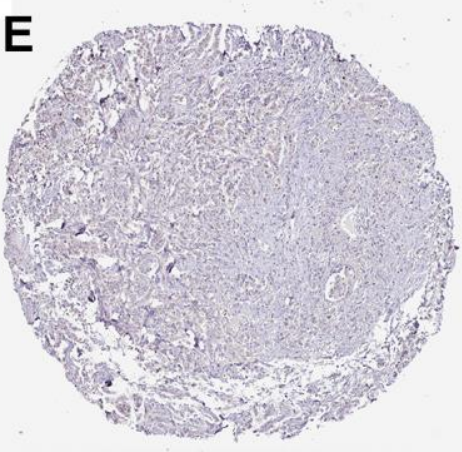

G

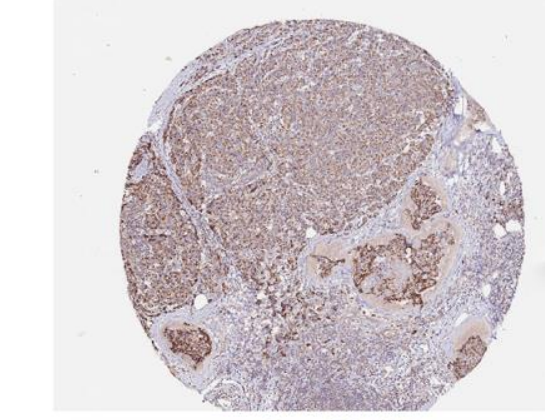

J

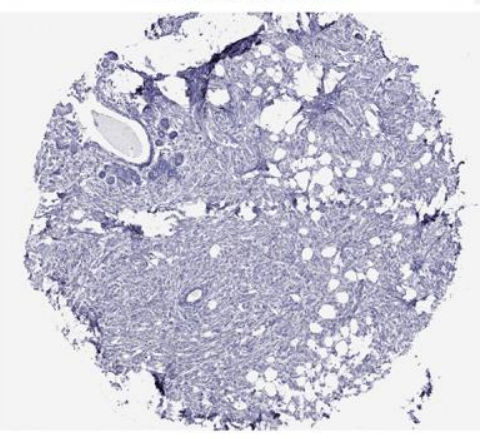

H

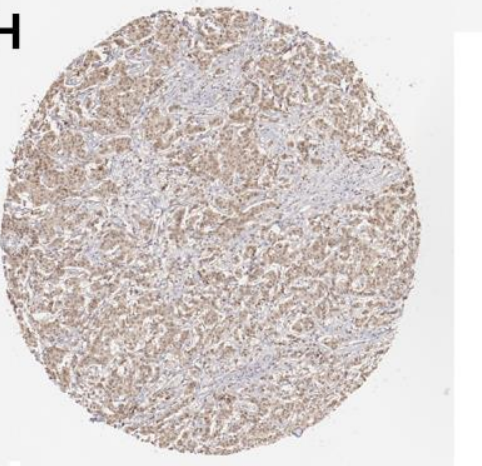

K

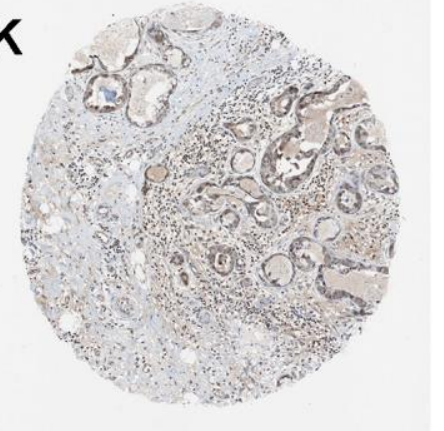

C

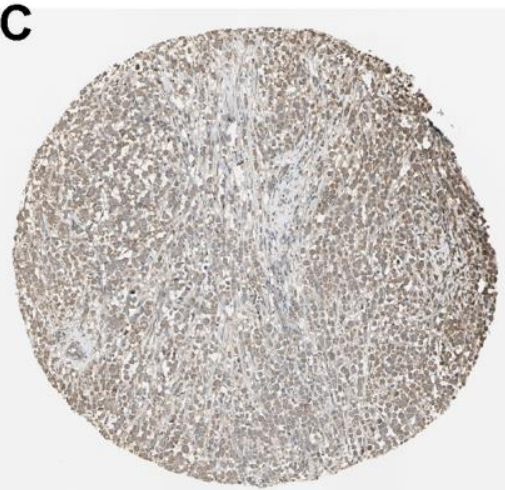

F
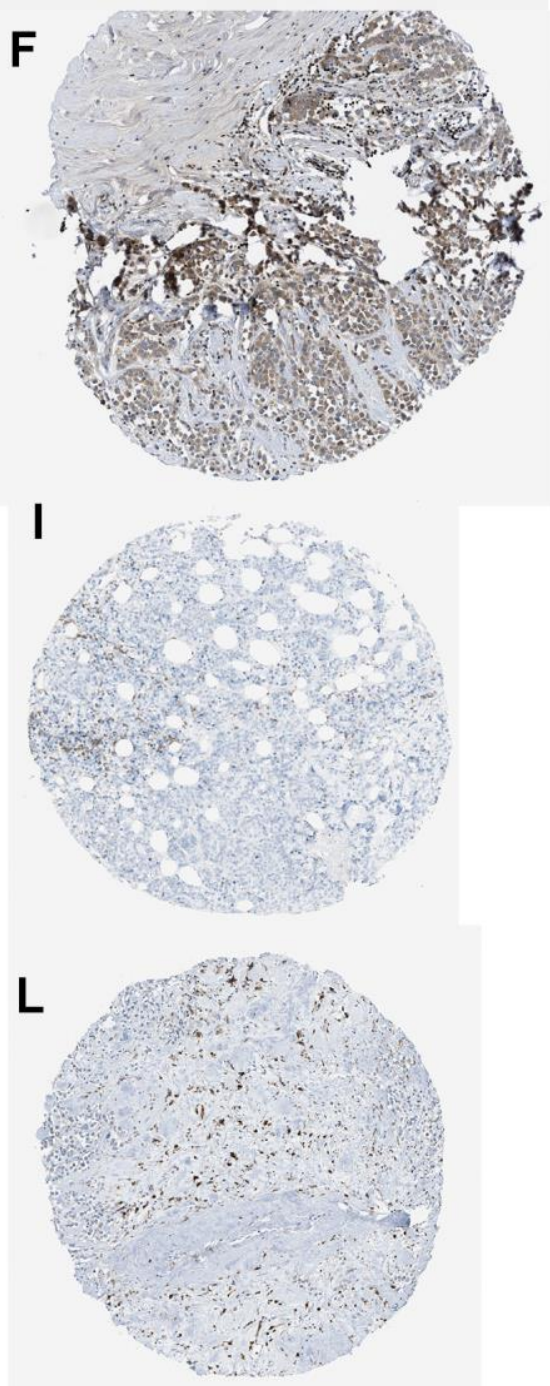

Figure 11. Immunohistochemistry for (A) DTX1 (https://www.proteinatlas.org/ENSG00000135144-DTX1/pathology/breast+cancer\#imid 18106719). (B) FEZ1 (https://www.proteinatlas.org/ENSG00000149557-FEZ1/pathology/breast+cancer\#imid 20550866). (C) FXYD3 (https:// www.proteinatlas.org/ENSG00000089356-FXYD3/pathology/breast+cancer\#imid 3109719). (D) FOXJ1 (https://www.proteinatlas.org/ ENSG00000129654-FOXJ1/pathology/breast+cancer\#imid 18961115). (E) HOXC13 (https://www.proteinatlas.org/ENSG00000123364HOXC13/pathology/breast+cancer\#imid 15073368). (F) LEF1 (https://www.proteinatlas.org/ENSG00000138795-LEF1/pathology/breast+ cancer\#imid 913343). (G) MMP25 (https://www.proteinatlas.org/ENSG00000008516-MMP25/pathology/breast+cancer\#imid 9651206). (H) NFE2 (https://www.proteinatlas.org/ENSG00000123405-NFE2/pathology/breast+cancer\#imid 927392). (I) NRG1 (https://www.proteinatlas. org/ENSG00000157168-NRG1/pathology/breast+cancer\#imid 3118350). (J) SCG2 (https://www.proteinatlas.org/ENSG00000171951-SCG2/ pathology/breast+cancer\#imid 20497272). (K) TP63 (https://www.proteinatlas.org/ENSG00000073282-TP63/pathology/breast+cancer\#imid 143251). (L) ULBP2 (https://www.proteinatlas.org/ENSG00000131015-ULBP2/pathology/breast+cancer\#imid 5232353). 
A

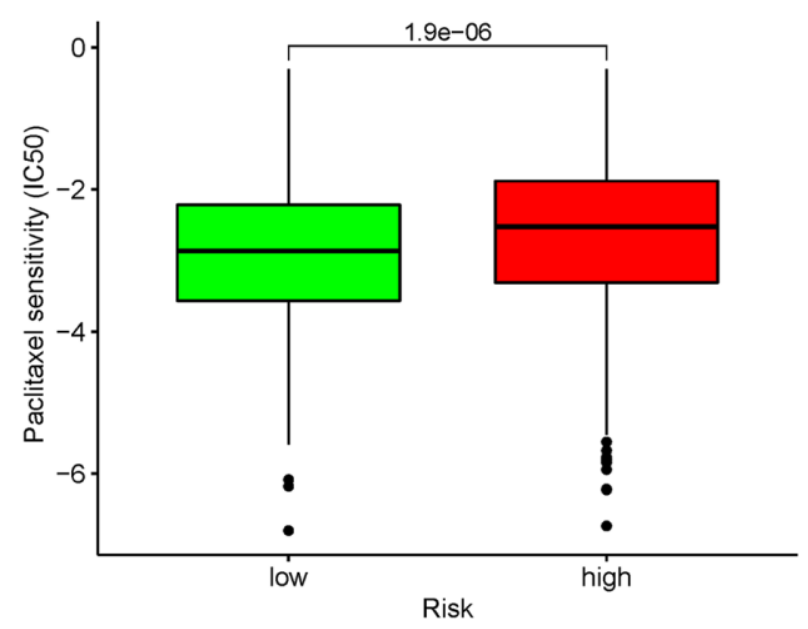

Risk 追 low 官 high

C

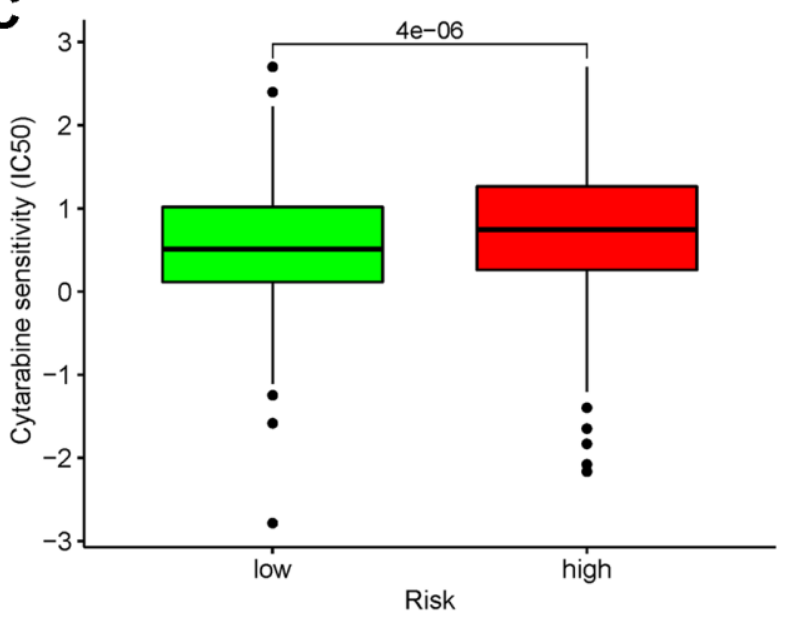

E

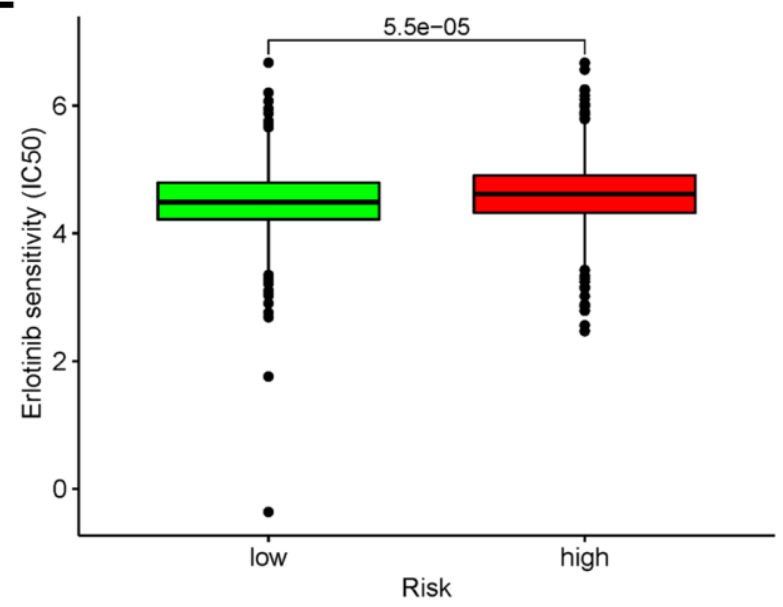

B Risk 皁 low 皋 high

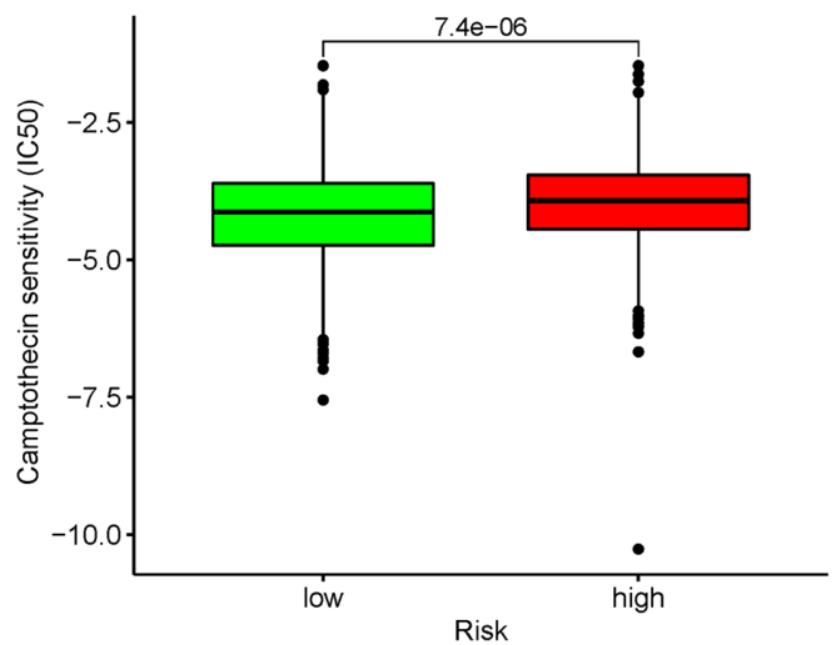

Risk 官 low 官 high

D

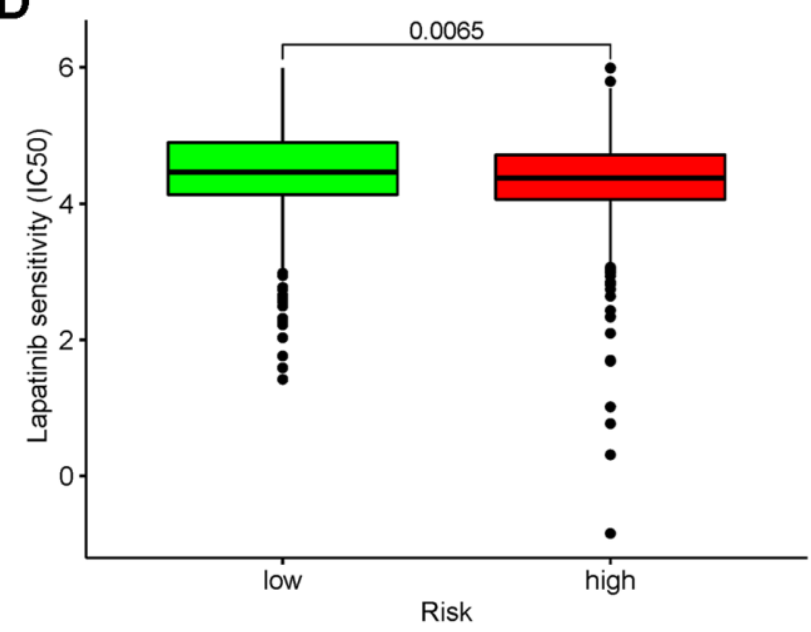

Risk 追 low 官 high

$\mathbf{F}$

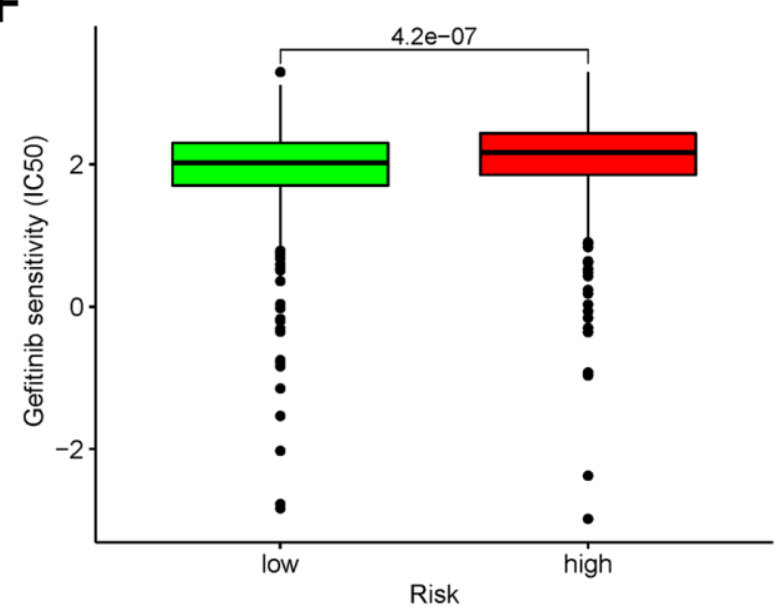

Figure 12. Durg-response analysis of (A) Paclitaxel. (B) Camptothecin. (C) Cytarabine. (D) Lapatinib. (E) Erlotinib. (F) Gefitinib. 
potential to predict prognosis and become a therapeutic target.

To construct a stable predictive model, we then conducted LASSO Cox regression analysis with DEGs to divide the breast cancer cases into low- and highrisk subsets. Finally, 17 DEGs were included in the risk score calculation. Next, we reviewed previous studies of these 17 DEGs (Table 2). Although the functions of some of these 17 DEGs were unclear and even controversial, and not all of them were reported to be related to breast cancer, we plan to perform additional research on these DEGs. To explore the potential signaling pathways among these 17 DEGs in the low- and high-risk groups, we performed the GSEA, from which we found that high-risk breast cancer was associated with histidine metabolism, protein export, and steroid hormone biosynthesis. Matboli et al. [47] demonstrated that histidine-rich glycoprotein expression was higher in basal-like breast cancer than in the normal-like subtype, while other evidence demonstrated that the basal-like breast cancer subtype had a worse prognosis [48]. Furthermore, Saha et al. [49] reported that steroid hormone receptors can drive cell cycle regulation and breast cancer progression, thereby controlling tumor proliferation. These enriched pathways suggested that the disease included in the high-risk group was more invasive and was associated with poorer survival than that in the low-risk group.

After further analysis, we found that the risk score was significantly correlated with clinical characteristics. Patients $\leq 60$ years of age with stage III, M0, and N0-1 breast cancer had significantly lower risk score than those $>60$ years with stage III-IV, M1, and N2-3 breast cancer. Moreover, we found that T4 breast cancer had the highest risk score, followed by T2-3 and T1. Notably, no significant differences were identified between stages I and II, stages III and IV, $\mathrm{T} 2$ and $\mathrm{T} 3, \mathrm{~N} 0$ and $\mathrm{N} 1$, or $\mathrm{N} 2$ and $\mathrm{N} 3$. We performed a correlation analysis for the risk score and several known breast cancer-associated genes, after which we found that TP53, KIT, MCL1, MAP3K1, JAK1, PDCD1, CTLA4, and CD274 were significantly negatively correlated with the risk score. The risk score was also negatively correlated with $\mathrm{T}$ cells, CD8+ T cells, cytotoxic lymphocytes, B lineage cells, NK cells, monocytic lineage cells, and myeloid dendritic cells, and was positively correlated with fibroblasts. From this analysis, we believed that the risk score was strongly associated with the TME. In breast cancer, many immune-related pathways are abnormally regulated, thereby influencing the microenvironment, such as through immune cell infiltration [50]. Based on current literature, some believe that the TME is a potential treatment target in breast cancer [51, 52]. To further demonstrate this conclusion, a drug sensitivity analysis was performed through which we identified significantly higher responses to agents, with the exception of lapatinib, in high-risk breast cancer. This special phenomenon was similar to what was observed in triple-negative breast cancer, which exhibited good chemotherapeutic sensitivity but poor prognosis [53-55]. Obviously, the risk score was strongly associated with the TME and was shown to predict chemotherapeutic and immunotherapeutic responses in breast cancer. However, no significant correlation was found between the risk score and breast cancer TMB, which requires additional research.

Based on these analyses, we believe that the risk score is valuable, but nevertheless, as a clinical predictive model, it should be better. Therefore, to further refine our model, we considered the risk score, clinical characteristics, and NMF clustering and constructed a nomogram. By summing the scores of these terms, we can predict the 1-, 3-, 5-year survival for every breast cancer patient, which might be a more precise and stable method. However, our analysis still has some limitations. First, our analysis only uses data from online databases, more real-word data are needed to further confirm our findings. Second, the detection of 17 DEGs would cost more than a model with fewer genes. However, our final prediction model has been confirmed to be effective, and since there are several other clinical prediction tools that require detection of more than 17 genes, our model is acceptable. Since breast cancer has varied subtypes, more detailed prediction models for the different subtypes should be constructed. We believe that these prediction models will be more powerful and cost-effective. Finally, although the HR of a single risk score was not very high, significant differences in OS and PFS as well as in AUC values were observed between the low- and high-risk score groups. To further improve the power of prediction model, we constructed a model using NMF clustering, the risk score, and clinical characteristics. Fortunately, our final nomogram model is shown to be better than any single factor.

In this study, we developed a novel predictive model using NMF clustering, clinical characteristics of breast cancer, and risk score based on 17 DEGs. The model was verified by randomly dividing the TCGA cohort into training and test cohorts, and separately analyzing the survival differences between low- and high-risk groups in these cohorts. Differences were observed in immune cell infiltration, clinical correlation, potential signaling pathways, and drug sensitivity. 
Table 2. Differentially expressed genes in the risk score calculation formula.

\begin{tabular}{|c|c|c|c|}
\hline Gene & Protein name & $\begin{array}{l}\text { Gene bank } \\
\text { accession number }\end{array}$ & Function \\
\hline WNT7B $[56,57]$ & Wnt7b protein & AY400071 & $\begin{array}{l}\text { WNT7B is involved in tumor growth promotion, } \\
\text { immunosuppression, angiogenesis, and cancer cell } \\
\text { dissemination. }\end{array}$ \\
\hline LEF1 [58] & $\begin{array}{l}\text { Lymphoid enhancer binding } \\
\text { factor } 1\end{array}$ & AY129650 & $\begin{array}{l}\text { LEF1 regulates glutathione metabolism, increases } \\
\text { chemotherapy resistance, and promotes breast } \\
\text { cancer brain metastasis. }\end{array}$ \\
\hline BCL2A1 $[59,60]$ & BCL2 related protein $\mathrm{A} 1$ & DQ081729 & $\begin{array}{l}\text { BCL2A1 represses hypoxia-induced cell death and } \\
\text { mitochondria-mediated apoptosis and promotes } \\
\text { tumor growth and metastasis. }\end{array}$ \\
\hline ULBP2 $[61,62]$ & UL16 binding protein 2 & AY358665 & $\begin{array}{c}\text { ULBP2 increases NK cell cytotoxicity resistance } \\
\text { and promotes cervical cancer proliferation, } \\
\text { invasion, and migration. }\end{array}$ \\
\hline GABRQ $[63,64]$ & $\begin{array}{l}\text { Gamma-aminobutyric acid } \\
\text { type A receptor subunit theta }\end{array}$ & KJ899212 & $\begin{array}{c}\text { GABRQ promotes hepatocellular cancer cell } \\
\text { proliferation. }\end{array}$ \\
\hline FXYD3 [65] & $\begin{array}{l}\text { FXYD domain containing ion } \\
\text { transport regulator } 3\end{array}$ & KJ891826 & FXYD3 promotes breast cancer cell proliferation. \\
\hline SCG2 [66] & Secretogranin II & KJ897788 & SCG2 enhances endothelial angiogenesis. \\
\hline FOXJ1 [67-70] & Forkhead box $\mathrm{J} 1$ & KJ891181 & $\begin{array}{l}\text { FOXJ1 promotes bladder cancer, prostate cancer, } \\
\text { hepatocellular cancer, and gastric cancer growth, } \\
\text { and metastasis. }\end{array}$ \\
\hline TP63 [71] & Tumor protein p63 & KR711025 & $\begin{array}{l}\text { TP63 increases expression of epidermal growth } \\
\text { factor receptor in breast cancer and increases the } \\
\text { response of breast cancer to cisplatin. }\end{array}$ \\
\hline RYR1 [72] & Ryanodine receptor 1 & AH006668 & $\begin{array}{l}\text { RYR } 1 \text { plays a vital role as a calcium channel in } \\
\text { excitation-contraction coupling in muscle. }\end{array}$ \\
\hline FEZ1 [73-76] & $\begin{array}{l}\text { Fasciculation and elongation } \\
\text { protein zeta } 1\end{array}$ & AF123653 & $\begin{array}{c}\text { FEZ1 suppresses prostate, esophageal, gastric, } \\
\text { bladder, and breast cancer progression, and } \\
\text { mediates promoter methylation-mediated } \\
\text { transcriptional downregulation and mitosis } \\
\text { inhibition. }\end{array}$ \\
\hline NRG1 [77] & Neuregulin 1 & CR450288 & $\begin{array}{l}\text { Heregulin isoforms encoded by NRG1 promote } \\
\text { tumor growth and induce metastasis. }\end{array}$ \\
\hline NFE2 [78] & Nuclear factor, erythroid 2 & CR450284 & $\begin{array}{c}\text { NFE2 promotes breast cancer cell growth in the } \\
\text { bone microenvironment, which leads to bone } \\
\text { metastasis; enhances expression of Wnt-related } \\
\text { molecules. }\end{array}$ \\
\hline HOXC13 [79] & Homeobox C13 & AF263466 & $\begin{array}{l}\text { HOXC13 facilitates cervical cancer cell } \\
\text { proliferation, migration, invasion and glycolysis } \\
\text { through the } \beta \text {-catenin/c-Myc signaling pathway. }\end{array}$ \\
\hline MMP25 [80] & Matrix metallopeptidase 25 & HF584190 & $\begin{array}{l}\text { High expression of MMP25 in head and neck } \\
\text { cancer is associated with a worse prognosis; } \\
\text { MMP25 is related to apoptosis, the KRS signaling } \\
\text { pathway, the PI3K/AKT/mTOR signaling } \\
\text { pathway, and the JAK/STAT signaling pathway. }\end{array}$ \\
\hline DTX1 $[81,82]$ & Deltex E3 ubiquitin ligase 1 & KT584324 & $\begin{array}{l}\text { DTX1 is a regulator of the Notch signaling } \\
\text { pathway and acts as an E3 ubiquitin ligase that can } \\
\text { repress Notch gene expression and inhibit early- } \\
\text { stage non-small cell lung carcinoma growth. }\end{array}$ \\
\hline
\end{tabular}




\section{Abbreviations}

AUC: Area under the curve; CI: Confidence interval; DCA: Decision curve analysis; DEG: Differentially expressed gene; ER: Estrogen receptor; FC: Fold change; FDR: False discovery rate; GEO: Gene Expression Omnibus; GO: Gene ontology; GSEA: Gene set enrichment analysis; HER2: Human epidermal growth factor receptor2; HR: Hazard ratio; KEGG: Kyoto Encyclopedia of Genes and Genomes; K-M: Kaplan-Meier; LASSO: Least absolute shrinkage and selection operator; MCP: Microenvironment cell population; NES: Normalized enrichment score; NMF: Negative matrix factorization; OS: Overall survival; PFS: Progression-free survival; PPI: Protein interaction; PR: Progesterone receptor; ROC: Receiver operating characteristic; TAM: Tumor-associated macrophage; TCGA: The Cancer Genome Atlas; TCGA-BRCA: The Cancer Genome Atlas Breast Invasive Carcinoma; THPA: The Human Protein Atlasdatabase; TMB; Tumor mutation burden; TME: Tumor microenvironment.

\section{AUTHOR CONTRIBUTIONS}

Kai Hong and Yingjue Zhang designed this study. Lingli Yao and Jiabo Zhang completed the data acquisition. Yu Guo and Xianneng Sheng performed work involving software. Kai Hong and Yingjue Zhang conducted the data analyses and manuscript writing. Lingli Yao and $\mathrm{Yu}$ Guo edited the manuscript. The final paper was checked by all authors.

\section{ACKNOWLEDGMENTS}

We acknowledge all online databases for providing their public resources and the patients who participated in these projects.

\section{CONFLICTS OF INTEREST}

The authors declare that they have no conflicts of interest.

\section{REFERENCES}

1. Ferlay J, Colombet $M$, Soerjomataram I, Parkin DM, Piñeros M, Znaor A, Bray F. Cancer statistics for the year 2020: An overview. Int J Cancer. 2021. [Epub ahead of print]. https://doi.org/10.1002/ijc.33588 PMID:33818764

2. Siegel RL, Miller KD, Jemal A. Cancer statistics. CA Cancer J Clin. 2020; 70:7-30.

https://doi.org/10.3322/caac.21590

PMID:31912902
3. Kroenke $\mathrm{CH}$, Michael $\mathrm{YL}$, Poole EM, Kwan ML, Nechuta S, Leas E, Caan BJ, Pierce J, Shu XO, Zheng Y, Chen WY. Postdiagnosis social networks and breast cancer mortality in the After Breast Cancer Pooling Project. Cancer. 2017; 123:1228-37.

https://doi.org/10.1002/cncr.30440 PMID:27943274

4. Yeh IT, Mies C. Application of immunohistochemistry to breast lesions. Arch Pathol Lab Med. 2008; 132:349-58. https://doi.org/10.5858/2008-132-349-AOITBL PMID: 18318578

5. Fougner C, Bergholtz H, Norum JH, Sørlie T. Redefinition of claudin-low as a breast cancer phenotype. Nat Commun. 2020; 11:1787. https://doi.org/10.1038/s41467-020-15574-5 PMID: $\underline{32286297}$

6. Gao L, Li Q. Identification of Novel Pyroptosis-Related IncRNAs Associated with the Prognosis of Breast Cancer Through Interactive Analysis. Cancer Manag Res. 2021; 13:7175-86. https://doi.org/10.2147/CMAR.S325710 PMID:34552353

7. Wang $X$, Li C, Chen T, Li W, Zhang H, Zhang D, Liu Y, Han D, Li Y, Li Z, Luo D, Zhang N, Yang Q. Identification and Validation of a Five-Gene Signature Associated With Overall Survival in Breast Cancer Patients. Front Oncol. 2021; 11:660242. https://doi.org/10.3389/fonc.2021.660242 PMID:34513664

8. Hoskins KF, Danciu OC, Ko NY, Calip GS. Association of Race/Ethnicity and the 21-Gene Recurrence Score With Breast Cancer-Specific Mortality Among US Women. JAMA Oncol. 2021; 7:370-8. https://doi.org/10.1001/jamaoncol.2020.7320 PMID:33475714

9. Parker JS, Mullins $M$, Cheang $M C$, Leung $S$, Voduc $D$, Vickery T, Davies S, Fauron C, He X, Hu Z, Quackenbush JF, Stijleman IJ, Palazzo J, et al. Supervised risk predictor of breast cancer based on intrinsic subtypes. J Clin Oncol. 2009; 27:1160-7. https://doi.org/10.1200/JCO.2008.18.1370 PMID:19204204

10. Cardoso F, van't Veer $\amalg$, Bogaerts J, Slaets L, Viale G, Delaloge S, Pierga JY, Brain E, Causeret S, DeLorenzi M, Glas AM, Golfinopoulos V, Goulioti T, et al, and MINDACT Investigators. 70-Gene Signature as an Aid to Treatment Decisions in Early-Stage Breast Cancer. N Engl J Med. 2016; 375:717-29.

https://doi.org/10.1056/NEJMoa1602253 PMID:27557300

11. Blighe K, Rana S, Lewis MJRPV. EnhancedVolcano: Publication-ready volcano plots with enhanced colouring and labeling. R package version. 2019; 1. 
12. Kolde R, Kolde M. Package 'pheatmap'. R package. 2015; $1: 790$.

13. Smyth GK. Limma: linear models for microarray data. Bioinformatics and computational biology solutions using $\mathrm{R}$ and Bioconductor. Springer, New York, NY. 2005; 397-420. https://doi.org/10.1007/0-387-29362-0 23

14. Leek JT, Johnson WE, Parker HS, Jaffe AE, Storey JD. The sva package for removing batch effects and other unwanted variation in high-throughput experiments. Bioinformatics. 2012; 28:882-3.

https://doi.org/10.1093/bioinformatics/bts034 PMID:22257669

15. Benjamini $Y$, Yekutieli D. The control of the false discovery rate in multiple testing under dependency. Ann Stat. 2001; 29:1165-88. https://doi.org/10.1214/aos/1013699998

16. Yu G, Wang LG, Han Y, He QY. clusterProfiler: an R package for comparing biological themes among gene clusters. OMICS. 2012; 16:284-7. https://doi.org/10.1089/omi.2011.0118 PMID:22455463

17. Kanehisa M, Goto S. KEGG: kyoto encyclopedia of genes and genomes. Nucleic Acids Res. 2000; 28:27-30. https://doi.org/10.1093/nar/28.1.27 PMID:10592173

18. The Gene Ontology Consortium. The Gene Ontology Resource: 20 years and still GOing strong. Nucleic Acids Res. 2019; 47:D330-8. https://doi.org/10.1093/nar/gky1055 PMID:30395331

19. Gaujoux R, Seoighe C. A flexible R package for nonnegative matrix factorization. BMC Bioinformatics. 2010; 11:367.

https://doi.org/10.1186/1471-2105-11-367 PMID:20598126

20. Goel MK, Khanna P, Kishore J. Understanding survival analysis: Kaplan-Meier estimate. Int J Ayurveda Res. 2010; 1:274-8.

https://doi.org/10.4103/0974-7788.76794

PMID:21455458

21. Becht E, Giraldo NA, Lacroix L, Buttard B, Elarouci N, Petitprez F, Selves J, Laurent-Puig P, Sautès-Fridman C, Fridman $\mathrm{WH}$, de Reyniès $A$. Estimating the population abundance of tissue-infiltrating immune and stromal cell populations using gene expression. Genome Biol. 2016; 17:218.

https://doi.org/10.1186/s13059-016-1070-5 PMID:27765066

22. Tibshirani R. Regression shrinkage and selection via the lasso. J R Stat Soc Series B Stat Methodol. 1996; 58:267-88. https://doi.org/10.1111/j.2517-6161.1996.tb02080.x
23. Muthukrishnan R, Rohini R. LASSO: A feature selection technique in predictive modeling for machine learning. 2016 IEEE international conference on advances in computer applications (ICACA). IEEE. 2016; 18-20.

https://doi.org/10.1109/ICACA.2016.7887916

24. Frost $\mathrm{HR}, \mathrm{Amos} \mathrm{Cl}$. Gene set selection via LASSO penalized regression (SLPR). Nucleic Acids Res. 2017; 45:e114.

https://doi.org/10.1093/nar/gkx291 PMID:28472344

25. Zou KH, O’Malley AJ, Mauri L. Receiver-operating characteristic analysis for evaluating diagnostic tests and predictive models. Circulation. 2007; 115:654-7. https://doi.org/10.1161/CIRCULATIONAHA.105.594929 PMID:17283280

26. Iasonos A, Schrag D, Raj GV, Panageas KS. How to build and interpret a nomogram for cancer prognosis. J Clin Oncol. 2008; 26:1364-70.

https://doi.org/10.1200/JCO.2007.12.9791 PMID:18323559

27. Vickers AJ, Elkin EB. Decision curve analysis: a novel method for evaluating prediction models. Med Decis Making. 2006; 26:565-74. https://doi.org/10.1177/0272989X06295361 PMID:17099194

28. Subramanian A, Tamayo P, Mootha VK, Mukherjee $S$, Ebert BL, Gillette MA, Paulovich A, Pomeroy SL, Golub TR, Lander ES, Mesirov JP. Gene set enrichment analysis: a knowledge-based approach for interpreting genome-wide expression profiles. Proc Natl Acad Sci USA. 2005; 102:15545-50.

https://doi.org/10.1073/pnas.0506580102 PMID:16199517

29. Kassambara A, Kassambara MA. Package 'ggpubr'. 2020.

30. Brunson JC. Ggalluvial: layered grammar for alluvial plots. J Open Source Softw. 2020; 5:2017. https://doi.org/10.21105/joss.02017

31. Wickham H, Francois R, Henry L, Müller K. dplyr: A grammar of data manipulation. $\mathrm{R}$ package version 0.4 . 2015; 3:p156.

32. Hadley W. Ggplot2: Elegrant graphics for data analysis. Springer. 2016.

33. Yang W, Soares J, Greninger P, Edelman EJ, Lightfoot $H$, Forbes S, Bindal N, Beare D, Smith JA, Thompson IR, Ramaswamy S, Futreal PA, Haber DA, et al. Genomics of Drug Sensitivity in Cancer (GDSC): a resource for therapeutic biomarker discovery in cancer cells. Nucleic Acids Res. 2013; 41:D955-61. https://doi.org/10.1093/nar/gks1111 PMID:23180760 
34. Geeleher P, Cox N, Huang RS. pRRophetic: an R package for prediction of clinical chemotherapeutic response from tumor gene expression levels. PLoS One. 2014; 9:e107468.

https://doi.org/10.1371/journal.pone.0107468

PMID:25229481

35. Zhang J, Shan B, Lin L, Dong J, Sun Q, Zhou Q, Chen J, Han X. Dissecting the Role of N6-MethylandenosineRelated Long Non-coding RNAs Signature in Prognosis and Immune Microenvironment of Breast Cancer. Front Cell Dev Biol. 2021; 9:711859.

https://doi.org/10.3389/fcell.2021.711859 PMID:34692676

36. Katsuta E, Huyser M, Yan L, Takabe K. A prognostic score based on long-term survivor unique transcriptomic signatures predicts patient survival in pancreatic ductal adenocarcinoma. Am J Cancer Res. 2021; 11:4294-307.

PMID: $\underline{34659888}$

37. Liu $\mathrm{M}$, Li $\mathrm{Q}$, Zhao $\mathrm{N}$. Identification of a prognostic chemoresistance-related gene signature associated with immune microenvironment in breast cancer. Bioengineered. 2021; 12:8419-34. https://doi.org/10.1080/21655979.2021.1977768 PMID:34661511

38. Luo $D$, Yao $W$, Wang $Q$, Yang $Q$, Liu $X$, Yang $Y$, Zhang $W$, Xue $D, M a B$. The nomogram based on the 6-IncRNA model can promote the prognosis prediction of patients with breast invasive carcinoma. Sci Rep. 2021; 11:20863.

https://doi.org/10.1038/s41598-021-00364-w PMID:34675301

39. Sionov RV. Leveling Up the Controversial Role of Neutrophils in Cancer: When the Complexity Becomes Entangled. Cells. 2021; 10:2486. https://doi.org/10.3390/cells10092486 PMID:34572138

40. Chen Y, Song Y, Du W, Gong L, Chang H, Zou Z. Tumorassociated macrophages: an accomplice in solid tumor progression. J Biomed Sci. 2019; 26:78. https://doi.org/10.1186/s12929-019-0568-z PMID:31629410

41. Hussain K, Cragg MS, Beers SA. Remodeling the Tumor Myeloid Landscape to Enhance Antitumor Antibody Immunotherapies. Cancers (Basel). 2021; 13:4904.

https://doi.org/10.3390/cancers13194904 PMID:34638388

42. Liang L, Yu J, Li J, Li N, Liu J, Xiu L, Zeng J, Wang T, Wu L. Integration of scRNA-Seq and Bulk RNA-Seq to Analyse the Heterogeneity of Ovarian Cancer Immune Cells and Establish a Molecular Risk Model. Front Oncol. 2021; 11:711020. https://doi.org/10.3389/fonc.2021.711020

PMID: $\underline{34621670}$

43. Pan C, Fujiwara $Y$, Horlad H, Iriki T, Shiraishi D, Komohara Y. Cyclic sulfur compounds targeting macrophage polarization into M2/protumor phenotype and their anti-tumor effects. Cancer Immunol Immunother. 2021. [Epub ahead of print]. https://doi.org/10.1007/s00262-021-03085-1 PMID:34655303

44. Qin Q, Ji H, Li D, Zhang H, Zhang Z, Zhang Q. Tumorassociated macrophages increase COX-2 expression promoting endocrine resistance in breast cancer via the PI3K/Akt/mTOR pathway. Neoplasma. 2021; 68:938-46.

https://doi.org/10.4149/neo $2021201226 N 1404$ PMID:34619972

45. Qiu Y, Chen T, Hu R, Zhu R, Li C, Ruan Y, Xie X, Li Y. Next frontier in tumor immunotherapy: macrophagemediated immune evasion. Biomark Res. 2021; 9:72.

https://doi.org/10.1186/s40364-021-00327-3 PMID:34625124

46. Feng R, Chen Y, Liu Y, Zhou Q, Zhang W. The role of B7H3 in tumors and its potential in clinical application. Int Immunopharmacol. 2021; 101:108153. https://doi.org/10.1016/j.intimp.2021.108153 PMID:34678689

47. Matboli M, Eissa S, Said H. Evaluation of histidinerich glycoprotein tissue RNA and serum protein as novel markers for breast cancer. Med Oncol. 2014; 31:897.

https://doi.org/10.1007/s12032-014-0897-4 PMID:24567057

48. Wang $\mathrm{H}$, Shi $\mathrm{Y}$, Chen $\mathrm{CH}$, Wen $\mathrm{Y}$, Zhou Z, Yang $\mathrm{C}$, Sun J, Du G, Wu J, Mao X, Liu R, Chen C. KLF5-induced IncRNA IGFL2-AS1 promotes basal-like breast cancer cell growth and survival by upregulating the expression of IGFL1. Cancer Lett. 2021; 515:49-62.

https://doi.org/10.1016/i.canlet.2021.04.016 PMID:34052325

49. Saha S, Dey S, Nath S. Steroid Hormone Receptors: Links With Cell Cycle Machinery and Breast Cancer Progression. Front Oncol. 2021; 11:620214. https://doi.org/10.3389/fonc.2021.620214 PMID:33777765

50. Noh MG, Kim SS, Kim YJ, Jung TY, Jung S, Rhee JH, Lee $\mathrm{JH}$, Lee JS, Cho JH, Moon KS, Park H, Lee KH. Evolution of the Tumor Microenvironment toward ImmuneSuppressive Seclusion during Brain Metastasis of Breast Cancer: Implications for Targeted Therapy. Cancers (Basel). 2021; 13:4895.

https://doi.org/10.3390/cancers13194895

PMID:34638378 
51. Rao Malla R, Marni R, Kumari S, Chakraborty A, Lalitha P. Microbiome Assisted Tumor Microenvironment: Emerging Target of Breast Cancer. Clin Breast Cancer. 2021; S1526-8209:00260-3. https://doi.org/10.1016/j.clbc.2021.09.002 PMID:34625387

52. Mehraj U, Ganai RA, Macha MA, Hamid A, Zargar MA, Bhat AA, Nasser MW, Haris M, Batra SK, Alshehri B, AlBaradie RS, Mir MA, Wani NA. The tumor microenvironment as driver of stemness and therapeutic resistance in breast cancer: New challenges and therapeutic opportunities. Cell Oncol (Dordr). 2021; 44:1209-29.

https://doi.org/10.1007/s13402-021-00634-9 PMID:34528143

53. Dent R, Trudeau M, Pritchard KI, Hanna WM, Kahn HK, Sawka CA, Lickley LA, Rawlinson E, Sun P, Narod SA. Triple-negative breast cancer: clinical features and patterns of recurrence. Clin Cancer Res. 2007; 13:4429-34.

https://doi.org/10.1158/1078-0432.CCR-06-3045 PMID:17671126

54. Foulkes WD, Smith IE, Reis-Filho JS. Triple-negative breast cancer. N Engl J Med. 2010; 363:1938-48. https://doi.org/10.1056/NEJMra1001389 PMID:21067385

55. Garrido-Castro AC, Lin NU, Polyak K. Insights into Molecular Classifications of Triple-Negative Breast Cancer: Improving Patient Selection for Treatment. Cancer Discov. 2019; 9:176-98.

https://doi.org/10.1158/2159-8290.CD-18-1177 PMID:30679171

56. Szebeni GJ, Vizler C, Kitajka K, Puskas LG. Inflammation and Cancer: Extra- and Intracellular Determinants of Tumor-Associated Macrophages as Tumor Promoters. Mediators Inflamm. 2017; 2017:9294018. https://doi.org/10.1155/2017/9294018 PMID:28197019

57. Yeo EJ, Cassetta L, Qian BZ, Lewkowich I, Li JF, Stefater JA 3rd, Smith AN, Wiechmann LS, Wang Y, Pollard JW, Lang RA. Myeloid WNT7b mediates the angiogenic switch and metastasis in breast cancer. Cancer Res. 2014; 74:2962-73.

https://doi.org/10.1158/0008-5472.CAN-13-2421 PMID:24638982

58. Blazquez R, Rietkötter E, Wenske B, Wlochowitz D, Sparrer D, Vollmer E, Müller G, Seegerer J, Sun X, Dettmer K, Barrantes-Freer A, Stange L, Utpatel K, et al. LEF1 supports metastatic brain colonization by regulating glutathione metabolism and increasing ROS resistance in breast cancer. Int J Cancer. 2020; 146:3170-83.

https://doi.org/10.1002/ijc.32742 PMID: $\underline{31626715}$
59. Yu R, Liang J, Liu Q, Niu XZ, Lopez DH, Hou S. The relationship of CCL4, BCL2A1, and NFKBIA genes with premature aging in women of Yin deficiency constitution. Exp Gerontol. 2021; 149:111316.

https://doi.org/10.1016/j.exger.2021.111316 PMID:33766622

60. Liang R, Yung MM, He F, Jiao P, Chan KK, Ngan HY, Chan DW. The Stress-Inducible BCL2A1 Is Required for Ovarian Cancer Metastatic Progression in the Peritoneal Microenvironment. Cancers (Basel). 2021; 13:4577.

https://doi.org/10.3390/cancers13184577 PMID:34572804

61. Cosman D, Müllberg J, Sutherland CL, Chin W, Armitage R, Fanslow W, Kubin M, Chalupny NJ. ULBPs, novel MHC class I-related molecules, bind to CMV glycoprotein UL16 and stimulate NK cytotoxicity through the NKG2D receptor. Immunity. 2001; 14:123-33. https://doi.org/10.1016/s1074-7613(01)00095-4 PMID:11239445

62. Liang HX, Li YH. MiR-873, as a suppressor in cervical cancer, inhibits cells proliferation, invasion and migration via negatively regulating ULBP2. Genes Genomics. 2020; 42:371-82.

https://doi.org/10.1007/s13258-019-00905-8 PMID:31902110

63. Li YH, Liu Y, Li YD, Liu YH, Li F, Ju Q, Xie PL, Li GC. GABA stimulates human hepatocellular carcinoma growth through overexpressed GABAA receptor theta subunit. World J Gastroenterol. 2012; 18:2704-11. https://doi.org/10.3748/wjg.v18.i21.2704 PMID:22690081

64. Lee D, Ha M, Hong CM, Kim J, Park SM, Park D, Sohn $\mathrm{DH}$, Shin HJ, Yu HS, Kim CD, Kang CD, Han ME, Oh SO, Kim YH. GABRQ expression is a potential prognostic marker for patients with clear cell renal cell carcinoma. Oncol Lett. 2019; 18:5731-8. https://doi.org/10.3892/ol.2019.10960 PMID:31788046

65. Yamamoto H, Okumura K, Toshima S, Mukaisho K, Sugihara $\mathrm{H}$, Hattori $\mathrm{T}$, Kato $\mathrm{M}$, Asano $\mathrm{S}$. FXYD3 protein involved in tumor cell proliferation is overproduced in human breast cancer tissues. Biol Pharm Bull. 2009; 32:1148-54.

https://doi.org/10.1248/bpb.32.1148 PMID:19571376

66. Luo MJ, Rao SS, Tan YJ, Yin H, Hu XK, Zhang Y, Liu YW, Yue T, Chen L, Li L, Huang YR, Qian YX, Liu ZZ, et al. Fasting before or after wound injury accelerates wound healing through the activation of proangiogenic SMOC1 and SCG2. Theranostics. 2020; 10:3779-92.

https://doi.org/10.7150/thno.44115 PMID:32206122 
67. Xian S, Shang D, Kong G, Tian Y. FOXJ1 promotes bladder cancer cell growth and regulates Warburg effect. Biochem Biophys Res Commun. 2018; 495:988-94.

https://doi.org/10.1016/j.bbrc.2017.11.063

PMID:29129693

68. Lan $\mathrm{Y}, \mathrm{Hu} \mathrm{X}$, Jiang $\mathrm{K}$, Yuan $\mathrm{W}$, Zheng $\mathrm{F}$, Chen $\mathrm{H}$. Significance of the detection of TIM-3 and FOXJ1 in prostate cancer. J BUON. 2017; 22:1017-21.

PMID:28952222

69. Wang J, Cai X, Xia L, Zhou J, Xin J, Liu M, Shang X, Liu J, Li $X$, Chen Z, Nie $Y$, Fan D. Decreased expression of FOXJ1 is a potential prognostic predictor for progression and poor survival of gastric cancer. Ann Surg Oncol. 2015; 22:685-92.

https://doi.org/10.1245/s10434-014-3742-2

PMID:24809300

70. Chen HW, Huang XD, Li HC, He S, Ni RZ, Chen $\mathrm{CH}$, Peng C, Wu G, Wang GH, Wang YY, Zhao YH, Zhang YX, Shen AG, Wang HM. Expression of FOXJ1 in hepatocellular carcinoma: correlation with patients' prognosis and tumor cell proliferation. Mol Carcinog. 2013; 52:647-59. https://doi.org/10.1002/mc.21904 PMID:22488567

71. Mendoza-Rodríguez MG, Ayala-Sumuano JT, GarcíaMorales L, Zamudio-Meza H, Pérez-Yepez EA, Meza I. IL-1 $\beta$ Inflammatory Cytokine-Induced TP63 Isoform $\triangle N P 63 \alpha$ Signaling Cascade Contributes to Cisplatin Resistance in Human Breast Cancer Cells. Int J Mol Sci. 2019; 20:270.

https://doi.org/10.3390/ijms20020270

PMID:30641908

72. Witherspoon JW, Meilleur KG. Review of RyR1 pathway and associated pathomechanisms. Acta Neuropathol Commun. 2016; 4:121. https://doi.org/10.1186/s40478-016-0392-6 PMID:27855725

73. Chen L, Zhu Z, Sun X, Dong XY, Wei J, Gu F, Sun YL, Zhou J, Dong JT, Fu L. Down-regulation of tumor suppressor gene FEZ1/LZTS1 in breast carcinoma involves promoter methylation and associates with metastasis. Breast Cancer Res Treat. 2009; 116:471-8. https://doi.org/10.1007/s10549-008-0147-6 PMID:18686028

74. Nonaka D, Fabbri A, Roz L, Mariani L, Vecchione A, Moore GW, Tavecchio L, Croce CM, Sozzi G. Reduced FEZ1/LZTS1 expression and outcome prediction in lung cancer. Cancer Res. 2005; 65:1207-12. https://doi.org/10.1158/0008-5472.CAN-04-3461 PMID:15735004
75. Califano D, Pignata S, Pisano C, Greggi S, Laurelli G, Losito NS, Ottaiano A, Gallipoli A, Pasquinelli R, De Simone V, Cirombella R, Fusco A, Chiappetta G. FEZ1/LZTS1 protein expression in ovarian cancer. J Cell Physiol. 2010; 222:382-6.

https://doi.org/10.1002/icp.21962

PMID:19885841

76. Toyooka S, Fukuyama Y, Wistuba II, Tockman MS, Minna JD, Gazdar AF. Differential expression of FEZ1/LZTS1 gene in lung cancers and their cell cultures. Clin Cancer Res. 2002; 8:2292-7.

PMID:12114433

77. Prentice LM, Shadeo A, Lestou VS, Miller MA, deLeeuw RJ, Makretsov N, Turbin D, Brown LA, Macpherson N, Yorida E, Cheang MC, Bentley J, Chia S, et al. NRG1 gene rearrangements in clinical breast cancer: identification of an adjacent novel amplicon associated with poor prognosis. Oncogene. 2005; 24:7281-9.

https://doi.org/10.1038/sj.onc.1208892 PMID:16027731

78. Zhang D, Iwabuchi S, Baba T, Hashimoto SI, Mukaida N, Sasaki SI. Involvement of a Transcription factor, Nfe2, in Breast Cancer Metastasis to Bone. Cancers (Basel). 2020; 12:3003. https://doi.org/10.3390/cancers12103003 PMID:33081224

79. Dai M, Song J, Wang L, Zhou K, Shu L. HOXC13 promotes cervical cancer proliferation, invasion and Warburg effect through $\beta$-catenin/c-Myc signaling pathway. J Bioenerg Biomembr. 2021; 53:597-608. https://doi.org/10.1007/s10863-021-09908-1 PMID:34309767

80. Liang Y, Guan C, Li K, Zheng G, Wang T, Zhang S, Liao G. MMP25 Regulates Immune Infiltration Level and Survival Outcome in Head and Neck Cancer Patients. Front Oncol. 2020; 10:1088.

https://doi.org/10.3389/fonc.2020.01088 PMID:32850314

81. Zheng L, Conner SD. PI5P4KY functions in DTX1mediated Notch signaling. Proc Natl Acad Sci USA. 2018; 115:E1983-90.

https://doi.org/10.1073/pnas.1712142115 PMID:29440432

82. Lee JH, Shin KM, Lee SY, Hong MJ, Choi JE, Kang HG, Do SK, Lee WK, Lee EB, Seok Y, Jeong JY, Yoo SS, Lee J, et al. Genetic Variant of Notch Regulator DTX1 Predicts Survival After Lung Cancer Surgery. Ann Surg Oncol. 2019; 26:3756-64. https://doi.org/10.1245/s10434-019-07614-2 PMID:31313037 


\section{SUPPLEMENTARY MATERIALS}

\section{Supplementary File}

Please browse Full Text version to see the data of Supplementary File 1.

Supplementary File 1. Codes for workflow. 